\title{
Inferring novel gene-disease associations using Medical Subject Heading Over-representation Profiles
}

\author{
Warren A Cheung ${ }^{1}$, BF Francis Ouellette ${ }^{2}$ and Wyeth W Wasserman ${ }^{3 *}$
}

\begin{abstract}
Background: MEDLINE ${ }^{\circledR} /$ PubMed $^{\circledR}$ currently indexes over 18 million biomedical articles, providing unprecedented opportunities and challenges for text analysis. Using Medical Subject Heading Over-representation Profiles (MeSHOPs), an entity of interest can be robustly summarized, quantitatively identifying associated biomedical terms and predicting novel indirect associations.

Methods: A procedure is introduced for quantitative comparison of MeSHOPs derived from a group of MEDLINE ${ }^{\circledR}$ articles for a biomedical topic (for example, articles for a specific gene or disease). Similarity scores are computed to compare MeSHOPs of genes and diseases.

Results: Similarity scores successfully infer novel associations between diseases and genes. The number of papers addressing a gene or disease has a strong influence on predicted associations, revealing an important bias for gene-disease relationship prediction. Predictions derived from comparisons of MeSHOPs achieves a mean 8\% AUC improvement in the identification of gene-disease relationships compared to gene-independent baseline properties.

Conclusions: MeSHOP comparisons are demonstrated to provide predictive capacity for novel relationships between genes and human diseases. We demonstrate the impact of literature bias on the performance of genedisease prediction methods. MeSHOPs provide a rich source of annotation to facilitate relationship discovery in biomedical informatics.
\end{abstract}

\section{Background}

A key focus of genomic medicine is the identification of relationships between phenotype and genotype. Genomewide association studies and exome/genome sequencing can reveal hundreds of candidate genes that may contribute to human disease. Given such a set of candidate genes, the prioritization of these genes for functional validation emerges as a key challenge in biomedical informatics [1]. Much focus has been placed upon the development of methods for the quantitative association of genes with disease [2].

Across biomedical research fields, scientific publications are the currency of knowledge. One near-universal

\footnotetext{
* Correspondence: wyeth@cmmt.ubc.ca

${ }^{3}$ Department of Medical Genetics, Centre for Molecular Medicine and Therapeutics at the Child and Family Research Institute, University of British Columbia, 980 W. 28th Ave, Vancouver, V5Z 4H4, Canada

Full list of author information is available at the end of the article
}

tool of life scientists to access this 'bibliome' is the MEDLINE $^{\mathbb{B}} /$ PubMed $^{\circledR}$ bibliographic database of the US National Library of Medicine (NLM), an actively maintained central repository for biomedical literature references [3]. As of 2010, over 18.5 million citations have been indexed by MEDLINE ${ }^{\circledR}$, at a modern rate exceeding 600,000 articles per year. Researchers face increasing difficulty navigating the growing body of published information in search of novel hypotheses. Encapsulating the bibliome for a disease or gene of interest in a form both understandable and informative is an increasingly important challenge in biomedical informatics $[4,5]$.

MEDLINE ${ }^{\circledR}$ provides data structures and curated annotations to assist scientists with the challenge of extracting pertinent articles from the bibliome of a biomedical entity. In an ongoing process, curators at the NLM identify key topics addressed in each publication and attach

\section{Biomed Central}


corresponding Medical Subject Headings (MeSH) [6] terms as annotations to each publication's record in MEDLINE $^{\circledR}$, covering over $97 \%$ of all PubMed-indexed citations. The National Center for Biotechnology Information (NCBI) PubMed portal utilizes the annotated $\mathrm{MeSH}$ terms to empower search of the citation database, extending the reach of users beyond naïve word matching to topic matching. As one of the constellation of NCBI resources, MEDLINE ${ }^{\circledR} /$ PubMed $^{\circledR}$ citations are further linked to gene entries in Entrez Gene where appropriate, with over 450,000 MEDLINE $^{\mathbb{B}} /$ PubMed $^{\mathbb{B}}$ citations linked to an Entrez Gene entry for a human gene.

The analysis of gene annotation properties and generelated literature is a core challenge within computational biology. Biomedical keywords for properties of genes, drawn from structured vocabularies, have been identified from unstructured gene annotations $[7,8]$, as well as directly from the primary literature [9-11]. Sets of genes can be analyzed to extract common annotated biomedical properties[12]. Assigned descriptive terms can be visualized as 'tag clouds' $[13,14]$. Comparison of gene annotation profiles can group genes - expanding proteinprotein interaction and phenotype networks, deriving regulatory networks and predicting other gene-gene relationships [15-20]. Annotation analysis enables prioritization of candidate genes in genetics studies [10,21-23], and, when integrated with other information sources, predicts novel properties of genes $[24,25]$. Existing tools and techniques demonstrate the value, and suggest a high potential impact, of annotation analysis. Significant research opportunities remain to improve annotation and annotation-based analysis methods.

The development of computational disease information resources has run parallel to the aforementioned genebased efforts. Controlled vocabularies for medical descriptions $[26,27]$ and disease-specific annotations $[28,29]$ are emerging to facilitate medical information systems. Analysis of biomedical annotations associated with disease literature, as well as networks of gene-disease association, have been constructed to investigate the common biological aspects underlying diseases $[9,30]$. In tandem with the curation of MEDLINE ${ }^{\circledR}$ by the NLM, a disease category of the Medical Subject Headings has been developed over 50 years, providing an extensive inventory of medical disorders. By 2011, 4,494 MeSH disease terms had been established.

Key to accelerating the identification of gene-disease relationships is the development of systematic approaches to quantitatively represent bibliometric information and infer functionally important relationships between entities. We have previously introduced MeSH Over-representation Profiles (MeSHOPs) as a convenient tool for constructing quantitative annotations for sets of papers in
MEDLINE $^{\circledR}$ where each paper refers to the same entity (such as a gene or a disease) [31]. To demonstrate the fidelity of the MeSHOP knowledge representation at measuring features important for prediction, we generate the $\mathrm{MeSHOPs}$ for human genes and diseases, and compare these MeSHOPs to predict novel associations. Predictive performance for gene-disease relationships is validated against co-occurrence in future publications and curated databases. Comparing MeSHOPs is demonstrated to be an effective way to identify novel relationships between genes and diseases.

\section{Results}

\section{Generation of MeSHOPs}

Disease and gene MeSHOPs provide a concise quantitative representation of the biomedical knowledge associated with an entity (Figure 1). For this study, two large classes of entities were analyzed - the human genes in Entrez Gene and the diseases specified formally within MeSH. MeSHOPs were generated for the classes 'disease' and 'human gene' by assessing the set of all linked MEDLINE $^{\circledR} /$ PubMed $^{\circledR}$ records for each entity.

All human genes present in Entrez Gene were considered (38,604 in Entrez Gene 2007). Two sources for genearticle linkages from Entrez Gene were evaluated: Gene Reference Into Function (GeneRIF) and gene2pubmed. GeneRIF is a curated set of links from Entrez Gene to MEDLINE $^{\mathbb{B}} / \mathrm{PubMed}^{\mathbb{B}}$ citations provided by annotators at the NLM and supplemented by validated public submissions that specifically refers to a described function of the gene [32]. These allow us to generate profiles based on articles highly relevant to the gene of interest, looking specifically at the subset of articles addressing the function of the gene. gene2pubmed is a set of links to MEDLINE ${ }^{\circledR}$ / PubMed $^{\mathbb{R}}$ articles relating to the gene, generally broader in scope than GeneRIFs, combining information from a panel of public databases. Due to its more general nature, gene2pubmed provides gene links for a larger proportion of the human genes, and links more articles for each gene as it is not limited to articles specifically addressing the function of the gene. We use these two sets of links to examine the effect of the quantity and specificity of geneassociated literature on prediction performance. GeneRIFs link 11,750 human genes to 142,396 articles. gene2pubmed links 26,510 human genes to 226,615 articles. The two MeSHOP gene article linkage collections are both used in the subsequently described validation.

Disease MeSHOPs were generated directly from MEDLINE $^{\circledR}$ via the curator-assigned MeSH disease terms. To generate MeSHOPs for diseases, all terms from the disease category - MeSH category C [33] - were used; a set composed of 4,229 unique terms in MeSH 2007 linking to over 8 million articles (of 16 million MEDLINE ${ }^{\mathbb{Q}}$ / PubMed $^{\circledR}$ articles). 


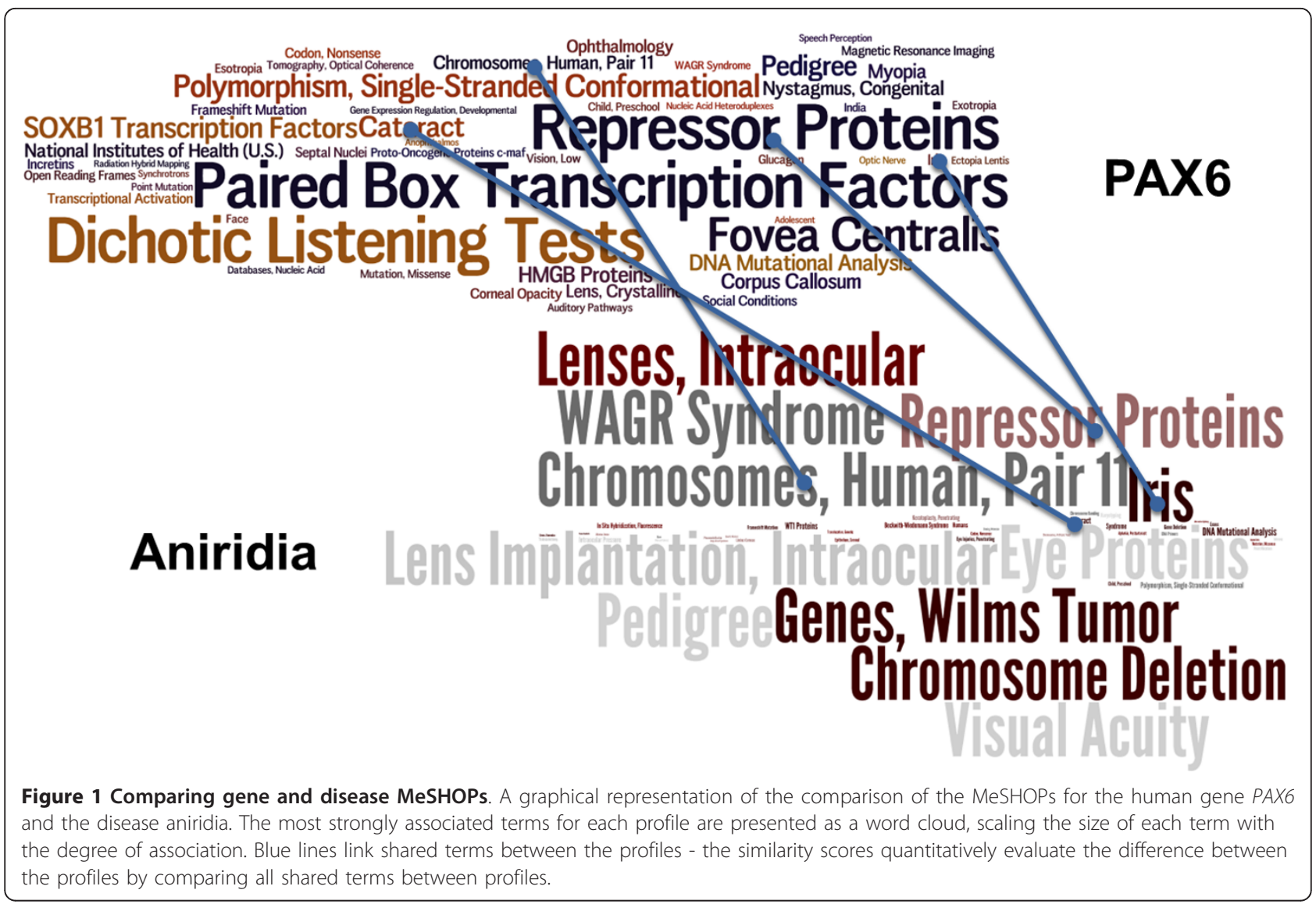

Quantitative comparison of gene and disease MeSHOPs for prediction of future co-occurrence in research publications

We hypothesize that a disease is likely to be associated with a gene if the disease MeSHOP is highly similar, under a quantitative profile comparison metric, to the gene MeSHOP. For example, a disease with a functional relationship to a gene may share $\mathrm{MeSH}$ terms between profiles, such as localization, metabolic pathways, cellular processes and symptoms, even if no links between the gene and the disease have been previously reported in the literature. When many biomedical terms are common between two profiles, the likelihood for a future association between the entities profiled is expected to increase.

Gene-disease relationship predictions using MeSHOPs from 2007 are validated here against gene-disease cooccurrences that appear in subsequent MEDLINE ${ }^{\circledR}$ (that is, using data not represented in the MeSHOPs). A validated prediction means one or more articles referring to both the gene and the disease was published during a subsequent time period as reported in a future MEDLINE ${ }^{\circledR}$ release (2009 or 2010). Two overlapping validation sets (2007 to 2009 and 2007 to 2010) were extracted: (i) 95,845 novel gene-disease co-occurrences for gene-article mappings from gene2pubmed for 2007 to 2009; (ii) 183,407 novel gene-disease co-occurrences for mappings from gene2pubmed for 2007 to 2010; (iii) 95,085 novel gene-disease co-occurrences for gene-article mappings from GeneRIF for 2007 to 2009; and (iv) 169,723 novel gene-disease cooccurrences for mappings from GeneRIF for 2007 to 2010. This approach is similar to the validation scheme presented in [34].

Using these validation sets, we evaluate scoring methods by computing the receiver operating characteristic (ROC) curve for predictions from analysis of the baseline 2007 data and reporting the area under the ROC curve (AUC). MeSHOP comparisons are defined as predictions of future disease-gene co-occurrence if a similarity score exceeds an applied threshold. To calculate the ROC curve, we classify the novel gene-disease co-occurrences appearing in the future gene MeSHOPs as 'true positives', and all other gene-disease pairings as 'true negatives', and for each possible threshold, we measure the sensitivity and the false positive rate. An ideal prediction method will produce an AUC score of 1, while random predictions are expected to generate an AUC score of 0.5.

Gene and disease predictive bibliometric baselines There is little quantitative information about baseline performance against which to compare gene-disease 
association prediction methods. Intrinsic characteristics of genes (for example, Entrez Gene identification number) were assessed for capacity to predict future genedisease term co-occurrence. For these controls, scores were obtained for quantitative characteristics of each gene. The scores represent gene-specific properties and do not account for disease properties; gene rankings are therefore the same for each disease in this baseline assessment. Likewise for the one examined intrinsic disease characteristic (number of $\mathrm{MeSH}$ terms), the diseases are ranked without regard to any specific gene. Using these baseline rankings, the AUC score was calculated for each indicated characteristic (Figure 2). Genespecific characteristics evaluated were: percentage of G/C mononucleotide content of the primary RefSeq transcript, total number of associated cDNA sequences reported in Entrez Gene, RefSeq transcript length, genomic length (from the annotated Ensembl gene/transcript start to end) and the Entrez Gene identification (ID) numbers. GC content, number of transcripts, transcript length and genomic length produced random AUC scores (approximately 0.5 ; Table 1 ).

Strikingly, Entrez Gene ID is predictive of a gene's likelihood to be linked to disease, with genes having lower Entrez Gene IDs more likely to co-occur with a disease in future publications (AUC ranging from 0.64 to 0.78 ). Entrez Gene IDs reflect no direct biological feature of the gene itself, but are sequentially assigned as genes are

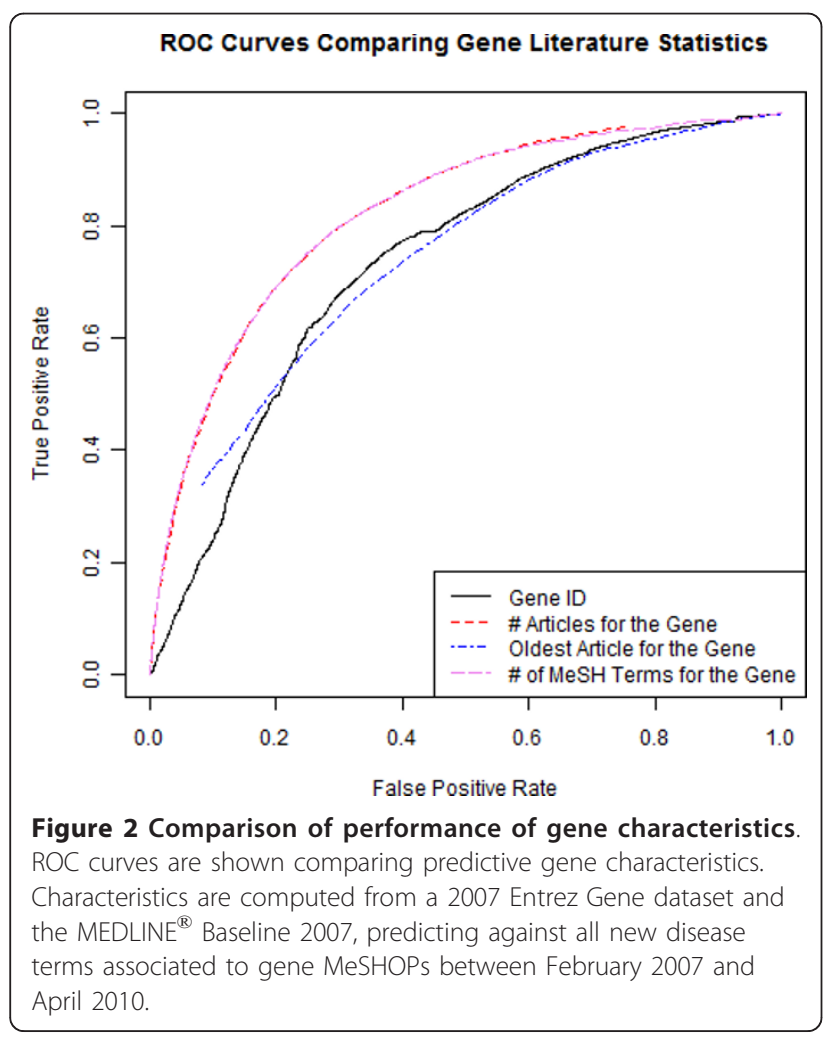

added to the database, indirectly measuring the length of time the gene has been studied. Therefore, the publication date of the oldest publication, estimating the length of publication history, and the number of publications, estimating the breadth of publication history, were examined for each gene using the Entrez Gene Feb 2007 dataset (Table 2). The AUC for the oldest publication for each gene exhibits higher predictive performance than the Entrez Gene ID number (AUC of 0.66 to 0.80 ), and the AUC for the number of publications is the highest of all gene-related characteristics observed (AUC of 0.73 to 0.85). Correlation of Entrez Gene ID to a richer and older publication history was reported by Leong and Kipling [35]. As the number of publications for a gene is correlated to the number of MeSH terms in the corresponding gene MeSHOP, it is not surprising that high AUC scores were obtained for $\mathrm{MeSH}$ term counts (Table 2; Figure 2).

As observed for gene-only score ranking, disease-only score rankings are non-random. The MeSH term counts for the disease MeSHOPs were predictive for future gene-disease co-occurrence in the literature (AUC from 0.76 to 0.90; Table 2; Figure 2). Across both gene and disease entities and across all validation sets, an entity that is highly annotated is substantially more likely to co-occur with another entity in future publications.

\section{MeSHOP similarity measures}

Quantitative comparison of gene and disease MeSHOPs improves prediction of future gene-disease co-occurrence over the baseline values established above. Sixteen distinct similarity measures were evaluated using AUC scores, from counting measures such as term overlap and term coverage to calculated measures such as Euclidean $\left(\mathrm{L}_{2}\right)$ and cosine distance of $P$-value profiles (Table 3). The scores evaluate the shared characteristics from both the gene and the disease MeSHOPs to make predictions. Three previously assessed baselines are presented for comparison: Entrez Gene ID, the number of terms in the gene MeSHOP, and the number of terms in the disease MeSHOP.

The MeSHOP prediction scores produced AUC ranging from random at 0.51 to a nearly optimal AUC of 0.99 , depending on the measure and the validation set (see Tables 4 and 5 for the AUC results of each score under each validation set). Each individual score was consistent across multiple validation sets and the GeneRIF or gene2pubmed article links, with the relative rank of the scores remaining nearly identical.

Although scores such as Term Overlap and Term Coverage (mean AUC of 0.87) have high scores compared to random, these are only on par with the best baseline scores (Table 6). The most effective similarity score is the $\mathrm{L}_{2}$ of log-p of overlapping terms only: 
Table 1 Performance of gene characteristics at predicting association with disease

\begin{tabular}{lcccccc}
\hline & \multicolumn{3}{c}{ gene2pubmed } & & GeneRIF \\
\cline { 2 - 7 } $\begin{array}{l}\text { Scoring } \\
\text { method }\end{array}$ & $\begin{array}{l}\text { Validation (02/ } \\
\mathbf{2 0 0 7 - 0 1 / 2 0 0 9 )}\end{array}$ & $\begin{array}{c}\text { Validation (02/ } \\
\mathbf{2 0 0 7 - 0 4 / 2 0 1 0 )}\end{array}$ & $\begin{array}{c}\text { CTD validation } \\
\mathbf{( 1 1 / 2 0 0 8 )}\end{array}$ & $\begin{array}{c}\text { Validation (02/ } \\
\mathbf{2 0 0 7 - 0 1 / 2 0 0 9 )}\end{array}$ & $\begin{array}{c}\text { Validation (02/ } \\
\text { 2007-04/2010) }\end{array}$ & $\begin{array}{c}\text { CTD validation } \\
(\mathbf{1 1 / 2 0 0 8 )}\end{array}$ \\
\hline $\begin{array}{l}\text { Percentage GC } \\
\text { content }\end{array}$ & 0.50 & 0.50 & 0.51 & 0.50 & 0.50 & 0.51 \\
$\begin{array}{l}\text { Number of } \\
\text { transcripts }\end{array}$ & 0.53 & 0.53 & 0.55 & 0.51 & 0.51 & 0.53 \\
$\begin{array}{l}\text { Transcript length } \\
\text { Genomic length }\end{array}$ & 0.51 & 0.52 & 0.50 & 0.52 & 0.52 & 0.53 \\
Gene ID & 0.52 & 0.52 & 0.50 & 0.51 & 0.51 & 0.52 \\
\hline
\end{tabular}

Characteristics were compared against the 02/2007-11/2008 validation sets using gene2pubmed and GeneRIF gene references, as well as the $11 / 2008$ Comparative Toxicogenomics Database (CTD) validation set. Gene characteristics were extracted from EnsEMBL. We compare the performance of these characteristics at predicting new gene-disease relationships in our validation sets (for the genes with mapped characteristics).

$$
\sqrt{\sum_{i \in(G \cap D)}\left(\log \left(g_{p}(i)\right)-\log \left(d_{p}(i)\right)\right)^{2}}
$$

where, $G$ and $D$ refer to the MeSH terms of gene and disease MeSHOPs, respectively, and $g_{p}(i)$ and $d_{p}(i)$ refer to the $P$-value for the MeSH term $i$ of the gene or disease profile, respectively), which generates a mean AUC of 0.94 (Table 6; Figure 3). Although bibliometric baseline scores - number of article links for a gene, number of $\mathrm{MeSH}$ terms in the gene MeSHOP and number of terms in the disease MeSHOP - are predictive of a future paper that refers to the gene and a disease, a distinct improvement in prediction is achieved by comparing gene and disease MeSHOPs using this $\mathrm{L}_{2}$ score, which will be used for MeSHOP comparisons going forward.

\section{Alternative validation methods}

As an alternative assessment to AUC scores, one can test assess a score's ability to correctly rank a list of candidate genes. For a particular disease and validation set, a list of $n$ genes (for example, $n=200$ genes) is constructed - one random disease-associated gene and $n-1$ random non-associated genes. The list of genes is ranked by the comparison score, and the test repeated.
In the case of a perfect metric, the mean test rank for the positive would be 1 , and in the case of completely random predictions, the mean rank would be $n / 2$. For test lists of 200 candidate genes, the top four MeSHOP comparison scores have mean test ranks from 12 to 20 , nearly all ranking on average within the top $10 \%$ of the list. To compare, the mean test rank for scoring by the number of gene $\mathrm{MeSH}$ terms is 39 and scoring using Gene ID is 59 (Table 6).

Another alternative metric is the mean average precision (MAP). Consistent with the other metrics, the most effective MeSHOP comparison score achieves a MAP of 0.94, with the number of disease terms and the number of gene terms achieving MAP of 0.89 and 0.79 , respectively (Table 7).

\section{Predicting association to disease}

Co-occurrence of gene and disease references in the same article does not confirm a functional relationship between the gene and the disease. Such co-occurrence could be observed for studies in which a gene-disease relationship is evaluated and found to be false or not significant, could arise from the gene and the disease appearing in separate sections, or could indicate a negative association between the gene and the disease. To

Table 2 Comparison of the performance of Entrez Gene ID to gene-related literature measuresin MEDLINE ${ }^{\circledR}$

\begin{tabular}{|c|c|c|c|c|c|c|}
\hline \multirow[b]{2}{*}{ Feature } & \multicolumn{3}{|c|}{ gene2pubmed } & \multicolumn{3}{|c|}{ GeneRIF } \\
\hline & $\begin{array}{c}\text { Validation AUC (02/ } \\
2007-01 / 2009)\end{array}$ & $\begin{array}{c}\text { Validation AUC (02/ } \\
2007-04 / 2010)\end{array}$ & $\begin{array}{l}\text { CTD validation } \\
(11 / 2008)\end{array}$ & $\begin{array}{c}\text { Validation AUC (02/ } \\
2007-01 / 2008)\end{array}$ & $\begin{array}{c}\text { Validation AUC (02/ } \\
2007-04 / 2010)\end{array}$ & $\begin{array}{l}\text { CTD validation } \\
(11 / 2008)\end{array}$ \\
\hline $\begin{array}{l}\text { Number of } \\
\text { MeSH terms }\end{array}$ & 0.74 & 0.73 & 0.81 & 0.80 & 0.85 & 0.82 \\
\hline $\begin{array}{l}\text { Number of } \\
\text { publications }\end{array}$ & 0.75 & 0.73 & 0.80 & 0.80 & 0.85 & 0.82 \\
\hline $\begin{array}{l}\text { Oldest } \\
\text { publication } \\
\text { (year) }\end{array}$ & 0.67 & 0.66 & 0.73 & 0.73 & 0.76 & 0.73 \\
\hline Gene ID & 0.64 & 0.64 & 0.66 & 0.69 & 0.75 & 0.73 \\
\hline
\end{tabular}

The oldest publication for a gene has comparable performance to Entrez Gene ID, as measured by the AUC; however, the number of publications for a gene proves to be even more predictive than the Entrez Gene ID. 
Table 3 Explanation of the scoring functions evaluated

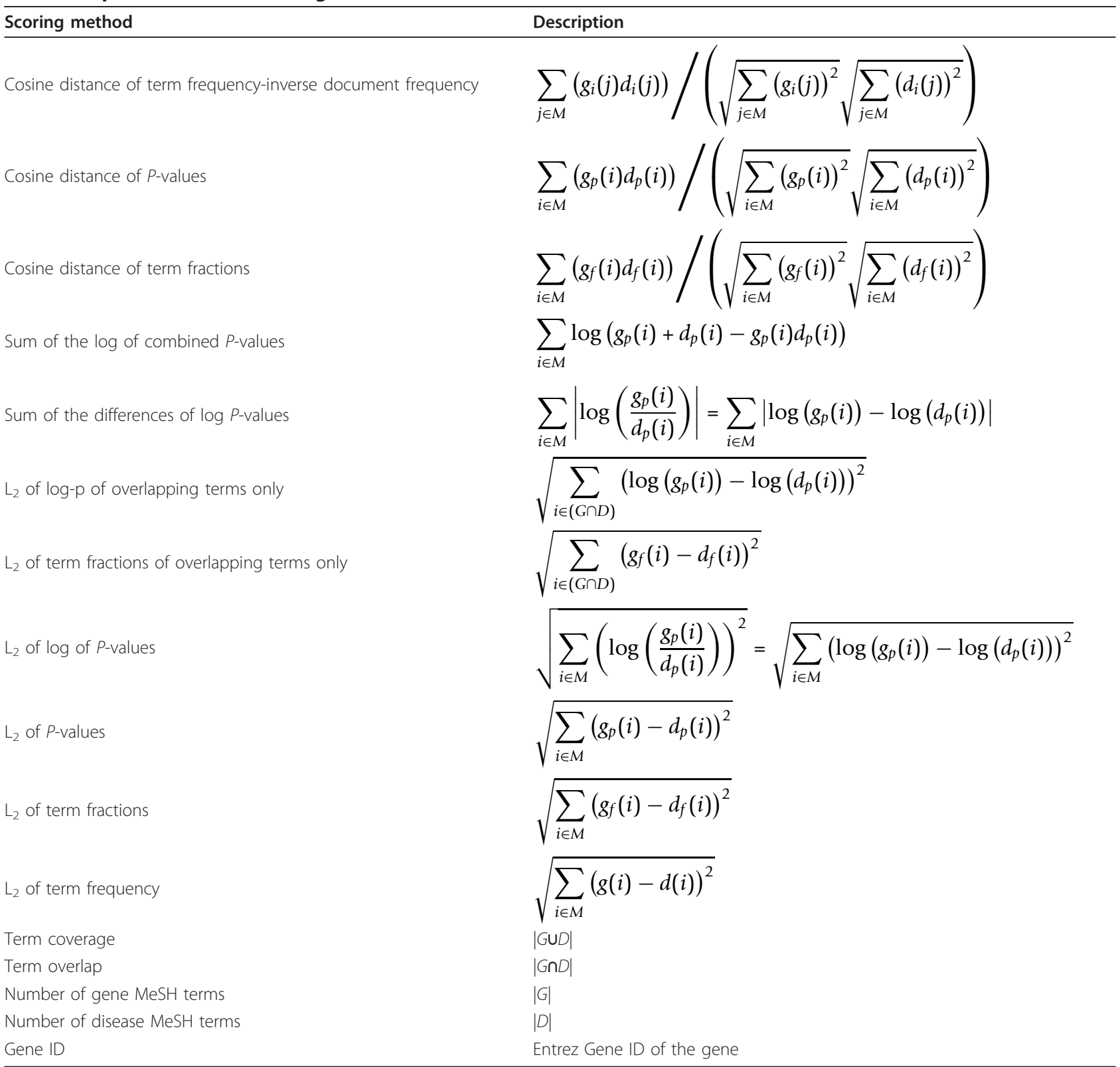

$M$ refers to the set of all MeSH terms, $G$ and $D$ to the MeSH terms for the gene and disease profile, respectively. $g(i), g_{f}(i), g_{p}(i)$ and $g_{i}(i)$ refer to the frequency, term fraction, hypergeometric $P$-value and term frequency-inverse document frequency for the MeSH term $i$ of the gene profile. $d_{(i)}, d_{f}(i), d_{p}(i)$ and $d_{i}(i)$ refer to the frequency, term fraction, hypergeometric $P$-value and term frequency-inverse document frequency for the MeSH term $i$ of the disease profile.

address this limitation of co-occurrence analysis, the predictive capacity of MeSHOP comparison is evaluated against curated gene-disease relationships from the Comparative Toxicogenomics Database (CTD) [36,37]. Relationships for genes identified as biomarkers, therapeutic targets in treatment or playing a role in the etiology of the disease are extracted from published literature and the Online Mendelian Inheritance in Man (OMIM) database by CTD curators, and the OMIMderived diseases are mapped onto corresponding $\mathrm{MeSH}$ disease terms [38]. These relationships are taken as the positive associations for ROC curve analysis to assess the MeSHOP predictions.

Performance of the MeSHOP scores on the CTD validation sets are consistent with the performance seen when inferring novel disease terms for gene profiles bibliometric baselines exhibiting up to AUC 0.85 while the best MeSHOP similarity scores achieve AUC over 0.9 (Table 2; Figures 3 and 4). Results confirm the effectiveness of MeSHOP comparison to recover bona fide gene-disease relationships. AUC shift by less than 0.08 when compared to the updated CTD April 2010 gene- 
Table 4 Performance using GeneRIF as the gene-literature data source sets

\begin{tabular}{|c|c|c|c|c|c|c|c|}
\hline Scoring method & $\begin{array}{c}\text { Novel MEDLINE } \\
\text { validation AUC (02/ } \\
\text { 2007-01/2009) }\end{array}$ & $\begin{array}{c}\text { Novel MEDLINE } \\
\text { validation AUC (02/ } \\
2007-04 / 2010)\end{array}$ & $\begin{array}{c}\text { Pre-existing CTD } \\
\text { validation AUC } \\
(11 / 2008)\end{array}$ & $\begin{array}{c}\text { Novel CTD } \\
\text { validation AUC } \\
(11 / 2008-04 / \\
2010) \\
\end{array}$ & $\begin{array}{c}\text { Pre-existing } \\
\text { MEDLINE } \\
\text { validation AUC } \\
(02 / 2007) \\
\end{array}$ & $\begin{array}{l}\text { Mean } \\
\text { AUC }\end{array}$ & Rank \\
\hline $\begin{array}{l}\text { Cosine distance of term } \\
\text { frequency-inverse } \\
\text { document frequency }\end{array}$ & 0.90 & 0.89 & 0.93 & 0.91 & 0.98 & 0.92 & 2 \\
\hline $\begin{array}{l}\text { Cosine distance of } P \text { - } \\
\text { values }\end{array}$ & 0.56 & 0.57 & 0.60 & 0.56 & 0.53 & 0.56 & 15 \\
\hline $\begin{array}{l}\text { Cosine distance of term } \\
\text { fractions }\end{array}$ & 0.86 & 0.84 & 0.91 & 0.88 & 0.96 & 0.89 & 4 \\
\hline $\begin{array}{l}\text { Sum of the log of } \\
\text { combined } P \text {-values }\end{array}$ & 0.86 & 0.85 & 0.92 & 0.90 & 0.94 & 0.90 & 3 \\
\hline $\begin{array}{l}\text { Sum of the differences } \\
\text { of log } P \text {-values }\end{array}$ & 0.91 & 0.91 & 0.77 & 0.83 & 0.93 & 0.87 & 6 \\
\hline $\begin{array}{l}\mathrm{L}_{2} \text { of log-p of } \\
\text { overlapping terms only }\end{array}$ & 0.94 & 0.93 & 0.91 & 0.92 & 0.98 & 0.94 & 1 \\
\hline $\begin{array}{l}\mathrm{L}_{2} \text { of term fractions of } \\
\text { overlapping terms only }\end{array}$ & 0.56 & 0.55 & 0.55 & 0.56 & 0.51 & 0.55 & 16 \\
\hline$L_{2}$ of log of $P$-values & 0.90 & 0.90 & 0.76 & 0.83 & 0.93 & 0.86 & 9 \\
\hline$L_{2}$ of $P$-values & 0.90 & 0.90 & 0.76 & 0.81 & 0.92 & 0.86 & 11 \\
\hline $\mathrm{L}_{2}$ of term fractions & 0.86 & 0.85 & 0.89 & 0.88 & 0.94 & 0.88 & 5 \\
\hline$L_{2}$ of term frequency & 0.90 & 0.90 & 0.76 & 0.83 & 0.93 & 0.86 & 10 \\
\hline Term coverage & 0.91 & 0.90 & 0.77 & 0.83 & 0.93 & 0.87 & 7 \\
\hline Term overlap & 0.82 & 0.82 & 0.86 & 0.86 & 0.87 & 0.85 & 12 \\
\hline $\begin{array}{l}\text { Number of gene MeSH } \\
\text { terms }\end{array}$ & 0.74 & 0.73 & 0.80 & 0.80 & 0.81 & 0.78 & 13 \\
\hline $\begin{array}{l}\text { Number of disease } \\
\text { MeSH terms }\end{array}$ & 0.90 & 0.90 & 0.77 & 0.83 & 0.93 & 0.87 & 8 \\
\hline Gene ID & 0.64 & 0.64 & 0.69 & 0.69 & 0.66 & 0.66 & 14 \\
\hline
\end{tabular}

AUC of the described scoring methods were compared and tested on the validation. CTD, Comparative Toxicogenomics Database.

disease relationship data (Tables 4 and 5). Similarly, when validating the prediction of new CTD relationships under the MAP metric, the strongest performing comparison score achieves MAP of 0.94 , while the number of gene terms and the number of disease term bibliometric baselines achieve MAP of 0.88 and 0.78 , respectively (Table 7 ).

\section{Comparative assessment of predictions with a literature- based system: candidate genes for Alzheimer disease}

To place MeSHOP comparisons in relationship to a top literature-based candidate gene prediction tool, we evaluated predictions for Alzheimer disease (AD)-gene relationships by MeSHOP comparison and a leading tool. We identified the top 500 gene candidates (top $3 \%$ of genes) for AD identified by MeSHOP comparison and by the Génie system [39], plotting the relationships between the ranks in Figure 5. Génie trains a naive linear Bayesian classifier based on the articles for the disease topic, then uses this classifier to rank the genes based on the articles associated with a gene and its homologs. The top 50 candidate genes are most strongly correlated, overlapping for 32 of the genes (see Table 8 for the top 50 candidate genes). Within Table 8 , the gene candidates previously investigated in the context of AD are indicated (46 of 50 genes) with the number of articles in gene2pubmed for which both the gene and the AD MeSH term are attached. For Génie, 48 of the top 50 candidates co-occur with the AD MeSH term (not shown); a 49th gene Notch3 - co-occurs with AD in two abstracts (and thus was detected as direct associations by Genie) but these papers were not curated in the gene2pubmed or GeneRIF sets as Notch3-focused articles. MeSHOP comparison ranked Notch3 in the top 100 candidates for $\mathrm{AD}$, despite the lack of curated co-occurrence. Both systems provide highly relevant lists of genes, with MeSHOP analysis reporting more novel candidates in this particular case study. Focusing on these novel genes with no pre-existing links in the literature, the two methods both implicate the HTT gene, which is known to be the causative gene for the neurodegenerative disorder Huntington disease, MeSHOP comparison ranks the XRCC3 gene highly, a DNA repair gene that could be involved in apoptosis and neuronal cell death (both of which are mechanisms associated with $\mathrm{AD}$ in the literature). The most striking candidates identified may be the F2 and the F5 genes, which 
Table 5 Performance using gene2pubmed as the gene-literature data source

\begin{tabular}{|c|c|c|c|c|c|c|c|}
\hline Scoring method & $\begin{array}{c}\text { Novel MEDLINE } \\
\text { validation AUC (02/ } \\
2007-01 / 2009)\end{array}$ & $\begin{array}{c}\text { Novel MEDLINE } \\
\text { validation AUC (02/ } \\
2007-04 / 2010)\end{array}$ & $\begin{array}{c}\text { Pre-existing CTD } \\
\text { validation AUC } \\
(11 / 2008)\end{array}$ & $\begin{array}{c}\text { Novel CTD } \\
\text { validation AUC } \\
(11 / 2008-04 / \\
2010)\end{array}$ & $\begin{array}{c}\text { Pre-existing } \\
\text { MEDLINE } \\
\text { validation AUC } \\
(02 / 2007)\end{array}$ & $\begin{array}{l}\text { Mean } \\
\text { AUC }\end{array}$ & $\overline{\text { Rank }}$ \\
\hline $\begin{array}{l}\text { Cosine distance of term } \\
\text { frequency-inverse } \\
\text { document frequency }\end{array}$ & 0.92 & 0.91 & 0.95 & 0.93 & 0.98 & 0.94 & 2 \\
\hline $\begin{array}{l}\text { Cosine distance of } P_{-} \\
\text {values }\end{array}$ & 0.53 & 0.51 & 0.65 & 0.63 & 0.53 & 0.57 & 16 \\
\hline $\begin{array}{l}\text { Cosine distance of term } \\
\text { fractions }\end{array}$ & 0.90 & 0.89 & 0.93 & 0.91 & 0.96 & 0.92 & 5 \\
\hline $\begin{array}{l}\text { Sum of the log of } \\
\text { combined } P \text {-values }\end{array}$ & 0.91 & 0.89 & 0.94 & 0.94 & 0.94 & 0.92 & 3 \\
\hline $\begin{array}{l}\text { Sum of the differences } \\
\text { of } \log P \text {-values }\end{array}$ & 0.91 & 0.91 & 0.77 & 0.83 & 0.93 & 0.87 & 7 \\
\hline $\begin{array}{l}\mathrm{L}_{2} \text { of log-p of } \\
\text { overlapping terms only }\end{array}$ & 0.96 & 0.95 & 0.92 & 0.94 & 0.99 & 0.95 & 1 \\
\hline $\begin{array}{l}\mathrm{L}_{2} \text { of term fractions of } \\
\text { overlapping terms only }\end{array}$ & 0.64 & 0.62 & 0.57 & 0.60 & 0.53 & 0.59 & 15 \\
\hline$L_{2}$ of log of $P$-values & 0.90 & 0.90 & 0.76 & 0.83 & 0.93 & 0.86 & 10 \\
\hline$L_{2}$ of $P$-values & 0.89 & 0.89 & 0.75 & 0.81 & 0.92 & 0.86 & 12 \\
\hline$L_{2}$ of term fractions & 0.92 & 0.90 & 0.91 & 0.92 & 0.95 & 0.92 & 4 \\
\hline$L_{2}$ of term frequency & 0.90 & 0.90 & 0.76 & 0.82 & 0.93 & 0.86 & 11 \\
\hline Term coverage & 0.90 & 0.91 & 0.77 & 0.83 & 0.93 & 0.87 & 8 \\
\hline Term overlap & 0.91 & 0.89 & 0.90 & 0.92 & 0.90 & 0.90 & 6 \\
\hline $\begin{array}{l}\text { Number of gene MeSH } \\
\text { terms }\end{array}$ & 0.85 & 0.82 & 0.85 & 0.88 & 0.83 & 0.85 & 13 \\
\hline $\begin{array}{l}\text { Number of disease } \\
\text { MeSH terms }\end{array}$ & 0.90 & 0.90 & 0.76 & 0.83 & 0.93 & 0.86 & 9 \\
\hline Gene ID & 0.75 & 0.73 & 0.78 & 0.79 & 0.74 & 0.76 & 14 \\
\hline
\end{tabular}

AUC of the described scoring methods were compared and tested on the validation sets. CTD, Comparative Toxicogenomics Database.

Table 6 Summary of MeSHOP performance

\begin{tabular}{|c|c|c|c|c|}
\hline Scoring method & Mean AUC & AUC standard error & Mean test rank $(n=200)$ & Overall rank \\
\hline Cosine distance of term frequency-inverse document frequency & 0.93 & 0.03 & 15.03 & 2 \\
\hline Cosine distance of $P$-values & 0.57 & 0.05 & 87.25 & 16 \\
\hline Cosine distance of term fractions & 0.90 & 0.04 & 20.21 & 4 \\
\hline Sum of the log of combined $P$-values & 0.91 & 0.03 & 18.88 & 3 \\
\hline Sum of the differences of $\log P$-values & 0.87 & 0.06 & 26.97 & 7 \\
\hline$L_{2}$ of log-p of overlapping terms only & 0.94 & 0.03 & 12.06 & 1 \\
\hline$L_{2}$ of term fractions of overlapping terms only & 0.57 & 0.04 & 86.70 & 15 \\
\hline$L_{2}$ of log of $P$-values & 0.86 & 0.07 & 28.05 & 10 \\
\hline$L_{2}$ of $P$-values & 0.86 & 0.07 & 29.62 & 12 \\
\hline$L_{2}$ of term fractions & 0.90 & 0.03 & 20.39 & 5 \\
\hline$L_{2}$ of term frequency & 0.86 & 0.06 & 28.31 & 11 \\
\hline Term coverage & 0.87 & 0.06 & 27.14 & 8 \\
\hline Term overlap & 0.87 & 0.03 & 26.17 & 6 \\
\hline Number of gene MeSH terms & 0.81 & 0.05 & 38.69 & 13 \\
\hline Number of disease MeSH terms & 0.86 & 0.06 & 27.87 & 9 \\
\hline Gene ID & 0.71 & 0.06 & 58.78 & 14 \\
\hline
\end{tabular}

The AUC mean, standard deviation and ranking for the MeSHOP scores and the gene and disease baselines are described, over all validation sets and both GeneRIF and gene2pubmed reference sets. 


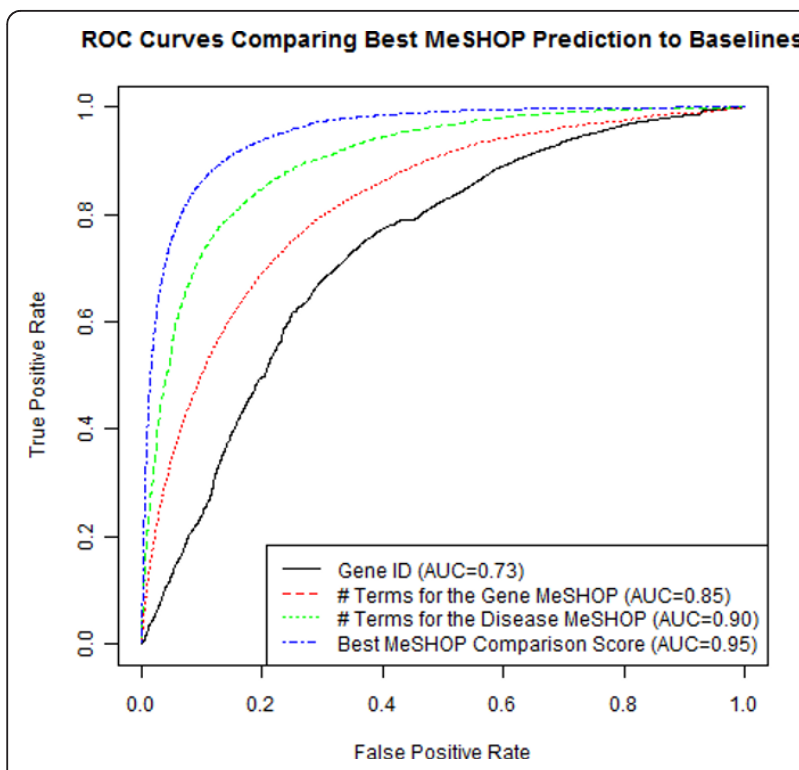

Figure 3 Comparing the performance of similarity scores to gene characteristics. ROC curves for the $L_{2}$ of log-p of overlapping terms gene-disease profile comparison score, compared against curves for Gene ID, the number of terms in the gene MeSHOP and the number of terms in the disease MeSHOP.

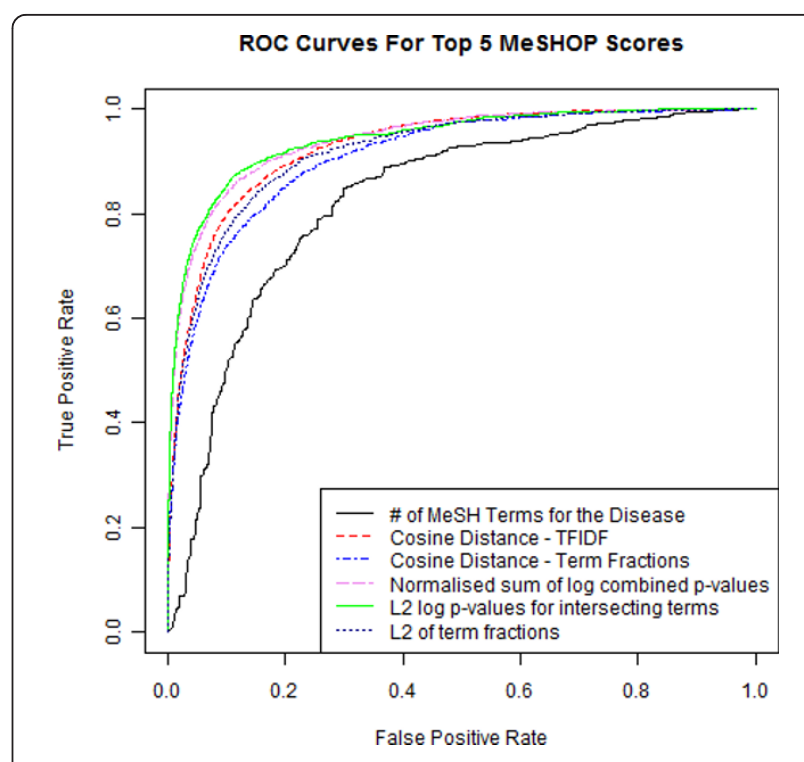

Figure $\mathbf{4}$ Comparing the performance of similarity scores. $\mathrm{ROC}$ curves are shown with AUC, computed for the top five similarity metrics and the disease number of MeSH terms baseline. These scores demonstrate predictions of gene-disease relationships using February 2007 data validated against the Comparative Toxicogenomics Database (11/2008) dataset. are involved in the blood coagulation pathway. The widely studied AD-related beta-amyloid protein has been shown to interact with fibrinogen, linking abnormalities in coagulation to the pathology of $\mathrm{AD}$ in recent papers $[40,41]$.

\section{Applied analyses for prediction of gene-disease relationships}

In the following sections MeSHOP gene-disease comparisons are performed for three distinct diseases: diabetes, pancreatic cancer and breast cancer. In each case,

Table 7 Mean average precision MeSHOP performance

\begin{tabular}{|c|c|c|c|c|}
\hline Scoring method & $\begin{array}{l}\text { Novel MEDLINE validation MAP (02/ } \\
2007-04 / 2010)\end{array}$ & Rank & $\begin{array}{l}\text { Novel CTD validation AUC (11/ } \\
2008-04 / 2010)\end{array}$ & Rank \\
\hline $\begin{array}{l}\text { Cosine distance of term frequency-inverse } \\
\text { document frequency }\end{array}$ & 0.87 & 11 & 0.92 & 4 \\
\hline Cosine distance of $P$-values & 0.55 & 15 & 0.66 & 15 \\
\hline Cosine distance of term fractions & 0.87 & 12 & 0.90 & 6 \\
\hline Sum of the log of combined $P$-values & 0.88 & 9 & 0.94 & 2 \\
\hline Sum of the differences of $\log P$-values & 0.90 & 3 & 0.79 & 9 \\
\hline$L_{2}$ of log-p of overlapping terms only & 0.94 & 1 & 0.95 & 1 \\
\hline$L_{2}$ of term fractions of overlapping terms only & 0.54 & 16 & 0.52 & 16 \\
\hline$L_{2}$ of log of $P$-values & 0.89 & 7 & 0.78 & 13 \\
\hline$L_{2}$ of $P$-values & 0.89 & 5 & 0.79 & 8 \\
\hline$L_{2}$ of term fractions & 0.90 & 2 & 0.92 & 5 \\
\hline$L_{2}$ of term frequency & 0.89 & 8 & 0.79 & 10 \\
\hline Term coverage & 0.90 & 4 & 0.79 & 11 \\
\hline Term overlap & 0.88 & 10 & 0.93 & 3 \\
\hline Number of gene MeSH terms & 0.81 & 13 & 0.88 & 7 \\
\hline Number of disease MeSH terms & 0.89 & 6 & 0.78 & 12 \\
\hline Gene ID & 0.69 & 14 & 0.74 & 14 \\
\hline
\end{tabular}

The mean average precision for the novel MEDLINE relationships (02/2007 to 04/2010) and the novel CTD relationships (11/2008 to 04/2010). In each trial, 100 positive relationships and 100 negative relationships were chosen uniformly at random, and the average precision was computed for each scoring method. The mean average precision presented here is calculated over 100 random trials for each validation set. 


\section{Alzheimer Disease Gene Ranks for Génie and MeSHOP Similarity Predictions}

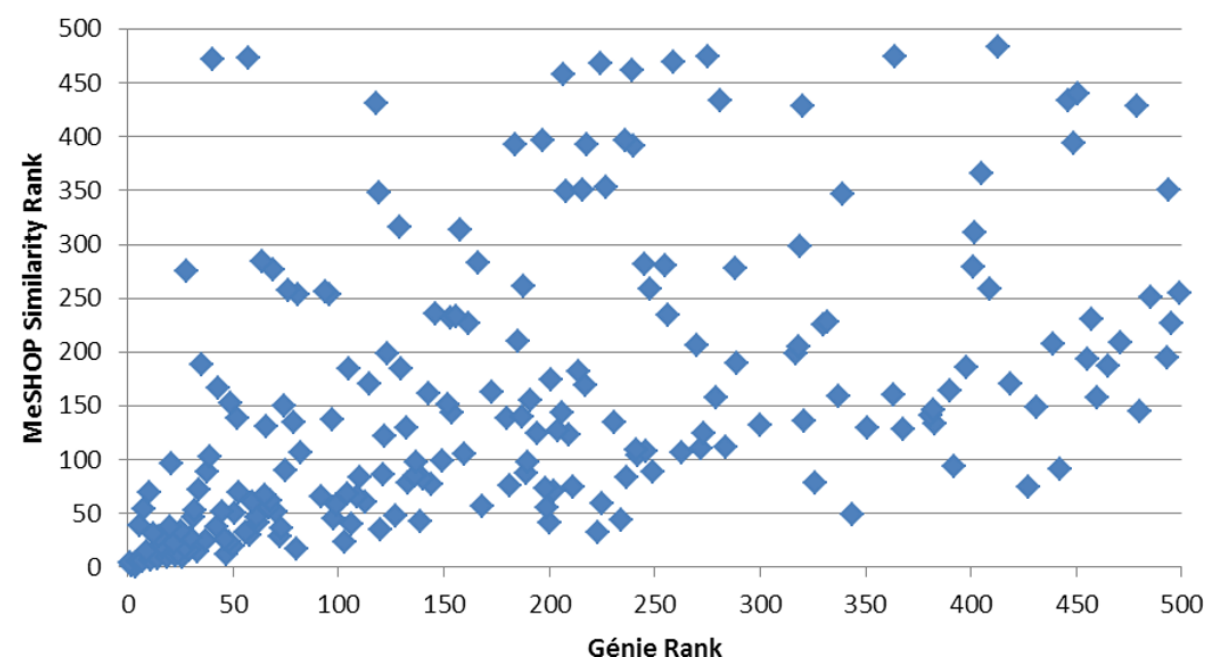

Figure $\mathbf{5}$ Comparison of the top $\mathbf{5 0 0}$ gene predictions for Alzheimer disease from Génie and MeSHOP similarity. The 215 genes ranked in the top 500 gene predictions for both Génie and MeSHOP Similarity are compared, showing a correlation of 0.38. Of the genes ranked in the top 500 by Génie, 79 did not have MeSHOPs and therefore did not have a computed MeSHOP similarity score to rank.

available knowledge about gene-disease relationships is identified and compared to MeSHOP comparison results. For each case, we report how many of the known genes are present in the top 500 genes (top 3\%), a number selected to be suitable for manual review of results by users.

To further depict the utility of the MeSHOP comparison method, we illustrate the application of MeSHOP comparisons to predict gene-disease pairs arising in a genomewide association study (GWAS) of diabetes. In 2007, Sladek et al. [42] reported a GWAS identifying eight novel risk loci for type 2 diabetes in a French cohort. Comparing the reported genes to the MeSHOP profiles (Table 9), TCF7L2 (Entrez Gene ID 6934) already had eight articles linking it to type 2 diabetes and hence a significant association was detected (corrected $P=0.018 /$ raw $P=1.3 \mathrm{e}-7$ ). As well, IDE (Entrez Gene ID 3416) had a weaker established link in four articles (corrected $P=0.50 /$ raw $P=$ $3.15 \mathrm{e}-6)$. No other genes emerging from the report had an established relationship to type 2 diabetes, and all six fell below the top $500 \mathrm{MeSHOP}$ candidates. The gene HHEX (Entrez Gene 3087), which was supported by results from a subsequent diabetes study (Diabetes Genetics Initiative of Broad Institute of Harvard and MIT, 2007), was the fourth highest ranking of the eight GWAS candidates. The results indicate the potential utility for MeSHOP comparisons to aide in the interpretation of GWAS results. The absence of a high ranking MeSHOP comparison score for a relationship does not imply the relationship does not exist, but rather may reflect the limitations in the literature pertaining to the gene.

To further show that MeSHOP comparison ranks can supplement research results, we examine a study by Jones et al. [43] combining sequenced RNA transcripts from protein-coding genes with microarray-based detection of homozygous deletions and amplifications in pancreatic cancer. Jones et al. introduced a scoring procedure to differentiate causal 'driver' genes from passenger genes, identifying 6 likely driver genes within a set of 83 candidate genes (where the 83 genes were identified as having at least 2 genetic alterations in the compiled data). In Table 10, the MeSHOP comparison scores for 'pancreatic neoplasms' are reported for the 83 identified genes. Five of the six Jones et al.-ranked driver candidate genes (TP53, CDKN2A, KRAS, TGFBR2, $S M A D 4)$ were represented in the top 500 MeSHOP predictions; MeSHOP comparisons did not identify the sixth gene, MLL3. The EP300 gene was low scoring in the Jones et al. rankings, although it was ranked fifth overall by MeSHOP comparisons. EP300 has been shown to be downregulated by microRNA in highly metastatic pancreatic ductal adenocarcinomas [44], demonstrating the capacity for MeSHOP comparison to identify candidate disease genes. The MeSHOP comparison provides a bibliometric view that both reinforces and complements existing analytical methods.

A recent publication examined the genomes of 100 breast cancer tumors for somatic mutations looking for 
Table 8 Top 50 Alzheimer disease candidate genes by MeSHOP similarity

\begin{tabular}{|c|c|c|c|c|c|}
\hline Rank & Gene ID & Gene name & Score & Génie rank & Alzheimer disease gene2pubmed references \\
\hline 1 & 348 & $A P O E$ & $1.18 \mathrm{E}+04$ & 4 & 812 \\
\hline 2 & 351 & $A P P$ & $1.22 \mathrm{E}+04$ & 2 & 576 \\
\hline 3 & 4137 & MAPT & $1.23 \mathrm{E}+04$ & 1 & 211 \\
\hline 4 & 5663 & PSEN1 & $1.27 \mathrm{E}+04$ & 3 & 249 \\
\hline 5 & 6622 & SNCA & $1.27 \mathrm{E}+04$ & 6 & 30 \\
\hline 6 & 627 & $B D N F$ & $1.28 \mathrm{E}+04$ & 9 & 47 \\
\hline 7 & 1312 & COMT & $1.29 \mathrm{E}+04$ & 87 & 10 \\
\hline 8 & 1401 & $C R P$ & $1.29 \mathrm{E}+04$ & 210 & 5 \\
\hline 9 & 6532 & SLC6A4 & $1.30 \mathrm{E}+04$ & 43 & 23 \\
\hline 10 & 3064 & HTT & $1.30 \mathrm{E}+04$ & 44 & 0 \\
\hline 11 & 5444 & PON1 & $1.30 \mathrm{E}+04$ & 204 & 16 \\
\hline 12 & 1813 & DRD2 & $1.30 \mathrm{E}+04$ & 114 & 1 \\
\hline 13 & 4846 & NOS3 & $1.30 \mathrm{E}+04$ & 118 & 18 \\
\hline 14 & 23621 & BACE1 & $1.30 \mathrm{E}+04$ & 5 & 86 \\
\hline 15 & 2950 & GSTP1 & $1.30 \mathrm{E}+04$ & 470 & 4 \\
\hline 16 & 5621 & PRNP & $1.31 \mathrm{E}+04$ & 12 & 28 \\
\hline 17 & 5054 & SERPINE1 & $1.31 \mathrm{E}+04$ & NA & 3 \\
\hline 18 & 1636 & $A C E$ & $1.31 \mathrm{E}+04$ & 32 & 45 \\
\hline 19 & 2952 & GSTI1 & $1.31 \mathrm{E}+04$ & NA & 3 \\
\hline 20 & 5071 & PARK2 & $1.31 \mathrm{E}+04$ & 13 & 6 \\
\hline 21 & 120892 & LRRK2 & $1.31 \mathrm{E}+04$ & 18 & 6 \\
\hline 22 & 3553 & $I L 1 B$ & $1.31 \mathrm{E}+04$ & 39 & 32 \\
\hline 23 & 4023 & $L P L$ & $1.31 \mathrm{E}+04$ & 172 & 7 \\
\hline 24 & 6647 & SOD1 & $1.31 \mathrm{E}+04$ & 36 & 6 \\
\hline 25 & 3356 & HTR2A & $1.31 \mathrm{E}+04$ & 121 & 16 \\
\hline 26 & 10 & NAT2 & $1.31 \mathrm{E}+04$ & 333 & 4 \\
\hline 27 & 7515 & $X R C C 1$ & $1.31 \mathrm{E}+04$ & NA & 2 \\
\hline 28 & 2944 & GSTM1 & $1.31 \mathrm{E}+04$ & NA & 3 \\
\hline 29 & 3552 & $I L 1 A$ & $1.31 \mathrm{E}+04$ & 30 & 36 \\
\hline 30 & 3569 & IL6 & $1.32 \mathrm{E}+04$ & 60 & 28 \\
\hline 31 & 5664 & PSEN2 & $1.32 \mathrm{E}+04$ & 7 & 78 \\
\hline 32 & 6648 & SOD2 & $1.32 \mathrm{E}+04$ & 131 & 4 \\
\hline 33 & 2153 & F5 & $1.32 \mathrm{E}+04$ & NA & 0 \\
\hline 34 & 338 & $A P O B$ & $1.32 \mathrm{E}+04$ & NA & 1 \\
\hline 35 & 7421 & $V D R$ & $1.32 \mathrm{E}+04$ & NA & 2 \\
\hline 36 & 2147 & F2 & $1.32 \mathrm{E}+04$ & NA & 0 \\
\hline 37 & 183 & $A G T$ & $1.32 \mathrm{E}+04$ & NA & 2 \\
\hline 38 & 1543 & CYP1A1 & $1.32 \mathrm{E}+04$ & NA & 1 \\
\hline 39 & 154 & ADRB2 & $1.32 \mathrm{E}+04$ & NA & 1 \\
\hline 40 & 4524 & MTHFR & $1.32 \mathrm{E}+04$ & 57 & 30 \\
\hline 41 & 1071 & CETP & $1.32 \mathrm{E}+04$ & 197 & 8 \\
\hline 42 & 3557 & $I L 1 R N$ & $1.32 \mathrm{E}+04$ & 278 & 7 \\
\hline 43 & 4318 & MMP9 & $1.32 \mathrm{E}+04$ & 219 & 5 \\
\hline 44 & 1565 & CYP2D6 & $1.32 \mathrm{E}+04$ & 238 & 9 \\
\hline 45 & 335 & $A P O A 1$ & $1.32 \mathrm{E}+04$ & 135 & 7 \\
\hline 46 & 7517 & XRCC3 & $1.32 \mathrm{E}+04$ & NA & 0 \\
\hline 47 & 3990 & LIPC & $1.32 \mathrm{E}+04$ & NA & 2 \\
\hline 48 & 4153 & MBL2 & $1.32 \mathrm{E}+04$ & NA & 1 \\
\hline 49 & 23435 & TARDBP & $1.32 \mathrm{E}+04$ & 10 & 10 \\
\hline 50 & 345 & APOC3 & $1.32 \mathrm{E}+04$ & NA & 2 \\
\hline
\end{tabular}

Genes are ranked by MeSHOP similarity score, and compared against the ranked list of Génie candidate genes for Alzheimer disease (a full analysis considering all possible orthologs). Also provided is a list of the number of articles related to Alzheimer disease in the gene2pubmed references for the gene, when present. Rows in bold indicate high-ranking predictions that have no prior association with Alzheimer disease in the literature. NA: gene not among the 566 genes ranked by Génie. 
Table 9 Summary of diabetes loci ranked by MeSHOP similarity

\begin{tabular}{llcccc}
\hline Locus & Entrez Gene ID & Predicted similarity score & Rank & Percentile & Direct association \\
\hline IDE & 3416 & $7.59 \mathrm{E}+07$ & 186 & 0.01 & $7.93 \mathrm{E}-02$ \\
TCF7L2 & 6934 & $5.91 \mathrm{E}+07$ & 421 & 0.02 & $3.30 \mathrm{E}-03$ \\
EXT2 & 2132 & $2.96 \mathrm{E}+07$ & 2616 & 0.10 & $\mathrm{NA}$ \\
HHEX & 3087 & $2.18 \mathrm{E}+07$ & 4631 & 0.18 & $\mathrm{NA}$ \\
KIF11 & 3832 & $1.87 \mathrm{E}+07$ & 5985 & 0.24 & $\mathrm{NA}$ \\
ALX4 & 60529 & $1.55 \mathrm{E}+07$ & 8313 & 0.33 & $\mathrm{NA}$ \\
SLC30A8 & 169026 & $1.55 \mathrm{E}+07$ & 8352 & 0.33 & $\mathrm{NA}$ \\
LOC387761 & 387761 & $\mathrm{NA}$ & $\mathrm{NA}$ & $\mathrm{NA}$ & $\mathrm{NA}$ \\
\hline
\end{tabular}

Loci identified by (Sladek et al. [42]) were ranked by MeSHOP similarity ( $\mathrm{L}_{2}$ of log-p of overlapping terms only). Direct association scores are the Bonferroni corrected $P$-values generated using the February 2007 datasets. NA

potential driver mutations [45], reporting 13 somatic cancer genes with seven or more observed mutations. Six of the thirteen reported genes are in the top thirteen MeSHOP candidates (Table 11). Within the top 500 MeSHOP candidates, including the set of 6, a total of 11 of the 13 somatic cancer genes were present. Top MeSHOP candidates that were not reported in the somatic breast cancer 'driver' gene list include several genes with known hereditary roles in breast cancer (for example, BRCA1 (MeSHOP rank 4) and BRCA2 (MeSHOP rank 8); Table 12).

Together these case studies demonstrate the utility of MeSHOP predictions as a complement to laboratory studies, providing support to a subset of candidate genes, revealing classes of genes not detected, and highlighting novel genes for further investigation.

\section{Availability of results}

Results are freely accessible on the web [46]. MeSHOP profiles can be browsed online for genes [47] and for diseases [48]. Gene-disease MeSHOP profile-based predictions can also be viewed online [49], listing results by disease (listing the most similar genes), or by gene (listing the most similar diseases), sorted by similarity score. Specific datasets relevant to this paper can be directly downloaded [50].

\section{Discussion}

Quantitative annotation profiles based on MeSH annotations, MeSHOPs, are shown to facilitate the identification of gene-disease relationships. In assessing the baseline properties of gene-disease relationship predictions, we observe a striking bias introduced by the level of annotation of the entities (gene and/or disease), such that simply predicting future gene-disease relationships based on the most studied genes (or diseases) is better than random guessing. Accounting for this bias, we demonstrate that comparison metrics using MeSHOPs has high capacity to predict future gene-disease cooccurrence in future research publications. Functional relationships between genes and diseases were predicted using reference collections, and shown to perform better than baselines. Overall, MeSHOP comparison is shown to be a useful tool for applied bioinformatics.

Strong performance of bibliometric baselines quantitatively indicates researchers may tend to explore additional relationships for existing well-characterized genes and diseases, echoing the imbalanced research activity seen by Agarwal and Searls [51]. On the other hand, this may rather reflect methodological biases emphasizing easier to characterize genes and diseases. Well-studied genes have pre-existing protocols and materials such as animal models and PCR primers. Well-studied diseases may be more commonly and reliably identified through better-established diagnostic methods and physician familiarity. Rather than bias, it may reflect properties of a subset of genes and diseases. Certain types of genes and diseases are involved in key processes, similar to multifunctional proteins in interaction networks [52]. A 'hub' gene involved in many pathways could cause many phenotypes when disrupted. Similarly, some phenotypes may actually be the result of many different molecular processes, each of which when misregulated due to a gene can cause different variations of the disease phenotype. As well, there are not just the causative genes for a disease, but many other genes may regulate the severity or provide protective immunity against the disease phenotype. Regardless of origin of these observed predictive biases, we strongly recommend that all future gene-disease prediction methods be contrasted to gene and disease bibliometric baseline characteristics - ideally against the strongest metrics that evaluate the degree of annotation (the number of MeSH terms in the MeSHOPs for the gene and disease). Bibliometric baseline comparison allows direct comparative assessment of the predictive ability of methods compared to these universal trends.

Previous work demonstrated gene length, cDNA length and protein length significantly differ between control and disease genes [53,54]. Our literature-based 
Table 10 Comparison of MeSHOP results for pancreatic cancer candidate genes

\begin{tabular}{|c|c|c|c|c|c|c|c|c|c|}
\hline Gene & $\begin{array}{l}\text { Entrez } \\
\text { gene }\end{array}$ & $\begin{array}{l}\text { Predicted } \\
\text { similarity }\end{array}$ & Rank & Percentile & Mutations & Deletions & $\begin{array}{c}\text { Passenger } \\
\text { probability: low } \\
\text { rates }\end{array}$ & $\begin{array}{c}\text { Passenger } \\
\text { probability: mid } \\
\text { rates }\end{array}$ & $\begin{array}{c}\text { Passenger } \\
\text { probability: high } \\
\text { rates }\end{array}$ \\
\hline TP53 & 7157 & $1.24 \mathrm{E}+08$ & 11 & 100 & 18 & 2 & $<0.001$ & $<0.001$ & $<0.001$ \\
\hline CDKN2A & 1029 & $8.29 \mathrm{E}+07$ & 135 & 99 & 2 & 16 & $<0.001$ & $<0.001$ & $<0.001$ \\
\hline KRAS & 3845 & $6.95 \mathrm{E}+07$ & 266 & 99 & 24 & 0 & $<0.001$ & $<0.001$ & $<0.001$ \\
\hline TGFBR2 & 7048 & $6.76 \mathrm{E}+07$ & 288 & 99 & 3 & 1 & $<0.001$ & 0.001 & 0.003 \\
\hline EP300 & 2033 & $6.37 E+07$ & 351 & 99 & 2 & 0 & 0.176 & 0.482 & 0.984 \\
\hline SMAD4 & 4089 & $6.14 \mathrm{E}+07$ & 386 & 98 & 8 & 6 & $<0.001$ & $<0.001$ & $<0.001$ \\
\hline ELN & 2006 & 5.57E+07 & 509 & 98 & 2 & 0 & 0.115 & 0.372 & 0.413 \\
\hline F8 & 2157 & $5.51 \mathrm{E}+07$ & 530 & 98 & 2 & 0 & 0.165 & 0.482 & 0.853 \\
\hline SCN5A & 6331 & $5.18 \mathrm{E}+07$ & 629 & 98 & 2 & 0 & 0.176 & 0.482 & 1.000 \\
\hline PRKCG & 5582 & 4.77E+07 & 798 & 97 & 2 & 0 & 0.115 & 0.372 & 0.413 \\
\hline TPO & 7173 & $4.71 \mathrm{E}+07$ & 831 & 97 & 2 & 0 & 0.115 & 0.375 & 0.694 \\
\hline PPP1R3A & 5506 & $4.50 \mathrm{E}+07$ & 946 & 96 & 2 & 0 & 0.115 & 0.477 & 0.694 \\
\hline SMARCA4 & 6597 & 4.04E+07 & 1243 & 95 & 2 & 0 & 0.062 & 0.183 & 0.413 \\
\hline COL5A1 & 1289 & $3.72 \mathrm{E}+07$ & 1518 & 94 & 2 & 0 & 0.176 & 0.482 & 0.984 \\
\hline MEPIA & 4224 & $3.38 \mathrm{E}+07$ & 1895 & 92 & 2 & 0 & 0.062 & 0.183 & 0.413 \\
\hline IL2RG & 3561 & $2.95 \mathrm{E}+07$ & 2652 & 89 & 1 & 0 & 0.004 & 0.016 & 0.997 \\
\hline ATP10A & 57194 & $2.77 \mathrm{E}+07$ & 2974 & 88 & 2 & 0 & 0.176 & 0.482 & 1.000 \\
\hline MYH2 & 4620 & $2.71 \mathrm{E}+07$ & 3063 & 88 & 2 & 0 & 0.165 & 0.477 & 0.853 \\
\hline GRIA3 & 2892 & $2.62 \mathrm{E}+07$ & 3281 & 87 & 1 & 1 & 0.017 & 0.069 & 0.999 \\
\hline$A B C A 7$ & 10347 & $2.56 \mathrm{E}+07$ & 3426 & 86 & 2 & 0 & 0.033 & 0.139 & 0.201 \\
\hline DLG3 & 1741 & $2.51 \mathrm{E}+07$ & 3540 & 86 & 1 & 0 & 0.003 & 0.015 & 0.997 \\
\hline DLC1 & 10395 & $2.47 \mathrm{E}+07$ & 3645 & 86 & 2 & 0 & 0.176 & 0.482 & 1.000 \\
\hline GLTSCR1 & 29998 & $2.06 \mathrm{E}+07$ & 5082 & 80 & 2 & 0 & 0.062 & 0.183 & 0.405 \\
\hline PCSK6 & 5046 & $2.02 \mathrm{E}+07$ & 5240 & 79 & 2 & 0 & 0.176 & 0.482 & 0.911 \\
\hline EVPL & 2125 & $2.00 \mathrm{E}+07$ & 5329 & 79 & 2 & 0 & 0.176 & 0.482 & 0.942 \\
\hline NRG2 & 9542 & $1.95 \mathrm{E}+07$ & 5537 & 78 & 2 & 0 & 0.165 & 0.477 & 0.853 \\
\hline SLITRK5 & 26050 & $1.93 \mathrm{E}+07$ & 5655 & 78 & 2 & 0 & 0.165 & 0.477 & 0.853 \\
\hline SEMA5B & 54437 & $1.92 \mathrm{E}+07$ & 5713 & 77 & 2 & 0 & 0.062 & 0.183 & 0.413 \\
\hline DPP6 & 1804 & $1.86 \mathrm{E}+07$ & 6025 & 76 & 3 & 0 & 0.009 & 0.079 & 0.201 \\
\hline PCDH15 & 65217 & $1.84 \mathrm{E}+07$ & 6162 & 76 & 4 & 0 & $<0.001$ & 0.017 & 0.048 \\
\hline FMN2 & 56776 & $1.82 \mathrm{E}+07$ & 6266 & 75 & 2 & 0 & 0.176 & 0.482 & 0.911 \\
\hline CACNA2D1 & 781 & 1.77E+07 & 6597 & 74 & 1 & 0 & 0.001 & 0.004 & 0.989 \\
\hline DLEC1 & 9940 & $1.70 \mathrm{E}+07$ & 7039 & 72 & 2 & 0 & 0.176 & 0.482 & 0.911 \\
\hline MLL3 & 58508 & $1.69 \mathrm{E}+07$ & 7090 & 72 & 6 & 0 & $<0.001$ & $<0.001$ & $<0.001$ \\
\hline$P B 1$ & 55193 & $1.63 \mathrm{E}+07$ & 7597 & 70 & 2 & 0 & 0.165 & 0.477 & 0.853 \\
\hline LRRN3 & 54674 & $1.60 \mathrm{E}+07$ & 7856 & 69 & 2 & 0 & 0.062 & 0.183 & 0.405 \\
\hline CYFIP1 & 23191 & $1.56 \mathrm{E}+07$ & 8225 & 67 & 3 & 0 & 0.009 & 0.079 & 0.201 \\
\hline$S F 3 B 1$ & 23451 & $1.55 \mathrm{E}+07$ & 8290 & 67 & 3 & 0 & 0.009 & 0.079 & 0.201 \\
\hline PXDN & 7837 & $1.55 \mathrm{E}+07$ & 8302 & 67 & 2 & 0 & 0.176 & 0.482 & 1.000 \\
\hline TNR & 7143 & 1.54E+07 & 8453 & 66 & 2 & 0 & 0.176 & 0.482 & 0.911 \\
\hline SN & 6614 & $1.53 \mathrm{E}+07$ & 8484 & 66 & 2 & 0 & 0.176 & 0.482 & 1.000 \\
\hline SLC6A15 & 55117 & $1.53 \mathrm{E}+07$ & 8488 & 66 & 2 & 0 & 0.062 & 0.183 & 0.405 \\
\hline ARIDIA & 8289 & $1.51 \mathrm{E}+07$ & 8688 & 66 & 2 & 0 & 0.176 & 0.482 & 0.984 \\
\hline SLC1AG & 6511 & $1.48 \mathrm{E}+07$ & 8908 & 65 & 2 & 0 & 0.115 & 0.477 & 0.694 \\
\hline LRRTM4 & 80059 & $1.46 \mathrm{E}+07$ & 9064 & 64 & 2 & 0 & 0.062 & 0.183 & 0.413 \\
\hline GALNT13 & 114805 & $1.42 \mathrm{E}+07$ & 9651 & 62 & 2 & 0 & 0.062 & 0.183 & 0.405 \\
\hline GUCY1A2 & 2977 & 1.39E+07 & 9964 & 60 & 2 & 0 & 0.062 & 0.183 & 0.405 \\
\hline ZNF638 & 27332 & 1.37E+07 & 10174 & 60 & 2 & 0 & 0.115 & 0.375 & 0.694 \\
\hline PDZRN3 & 23024 & 1.33E+07 & 10522 & 58 & 2 & 0 & 0.033 & 0.082 & 0.201 \\
\hline DOCK2 & 1794 & $1.33 \mathrm{E}+07$ & 10612 & 58 & 2 & 0 & 0.062 & 0.183 & 0.405 \\
\hline MIZF & 25988 & $1.32 \mathrm{E}+07$ & 10714 & 58 & 2 & 0 & 0.062 & 0.183 & 0.405 \\
\hline
\end{tabular}


Table 10 Comparison of MeSHOP results for pancreatic cancer candidate genes (Continued)

\begin{tabular}{|c|c|c|c|c|c|c|c|c|c|}
\hline $\mathrm{DACH} 2$ & 117154 & $1.30 E+07$ & 10883 & 57 & 1 & 1 & 0.022 & 0.088 & 1.000 \\
\hline ST6GAL2 & 84620 & $1.26 \mathrm{E}+07$ & 11302 & 55 & 2 & 0 & 0.115 & 0.375 & 0.694 \\
\hline KBTBD11 & 9920 & $1.19 \mathrm{E}+07$ & 12083 & 52 & 1 & 1 & 0.006 & 0.025 & 0.998 \\
\hline CNTN5 & 53942 & $1.18 \mathrm{E}+07$ & 12231 & 51 & 2 & 0 & 0.115 & 0.375 & 0.694 \\
\hline ABLIM2 & 84448 & 1.17E+07 & 12471 & 51 & 2 & 0 & 0.062 & 0.183 & 0.405 \\
\hline PCDH18 & 54510 & $1.14 \mathrm{E}+07$ & 12864 & 49 & 2 & 0 & 0.115 & 0.375 & 0.694 \\
\hline ADAMTS20 & 80070 & $1.09 \mathrm{E}+07$ & 13668 & 46 & 2 & 0 & 0.176 & 0.482 & 0.911 \\
\hline $\mathrm{CDH} 10$ & 1008 & $1.09 E+07$ & 13703 & 46 & 3 & 0 & $<0.001$ & 0.017 & 0.048 \\
\hline KIAA1024 & 23251 & $1.09 \mathrm{E}+07$ & 13715 & 46 & 2 & 0 & 0.115 & 0.375 & 0.694 \\
\hline TBX18 & 9096 & $1.08 \mathrm{E}+07$ & 13821 & 45 & 2 & 0 & 0.062 & 0.183 & 0.413 \\
\hline LRFN5 & 145581 & $1.07 \mathrm{E}+07$ & 13894 & 45 & 2 & 0 & 0.062 & 0.183 & 0.405 \\
\hline$D E P D C 2$ & 80243 & $1.07 \mathrm{E}+07$ & 13953 & 45 & 3 & 0 & 0.055 & 0.183 & 0.405 \\
\hline FMNL3 & 91010 & $1.05 \mathrm{E}+07$ & 14376 & 43 & 2 & 0 & 0.055 & 0.179 & 0.405 \\
\hline TM7SF4 & 81501 & $1.03 \mathrm{E}+07$ & 14681 & 42 & 2 & 0 & 0.055 & 0.179 & 0.405 \\
\hline OR1OR2 & 343406 & $1.02 \mathrm{E}+07$ & 15126 & 40 & 2 & 0 & 0.033 & 0.139 & 0.317 \\
\hline GPR133 & 283383 & $1.02 E+07$ & 15188 & 40 & 2 & 0 & 0.062 & 0.183 & 0.405 \\
\hline PCDH17 & 27253 & $1.01 \mathrm{E}+07$ & 15355 & 39 & 2 & 0 & 0.062 & 0.183 & 0.405 \\
\hline BAI3 & 577 & $9.58 \mathrm{E}+06$ & 16457 & 35 & 3 & 0 & 0.033 & 0.082 & 0.201 \\
\hline KIAA0774 & 23281 & $9.49 E+06$ & 16660 & 34 & 2 & 0 & 0.176 & 0.482 & 0.984 \\
\hline CTNNA2 & 1496 & $9.42 E+06$ & 16781 & 33 & 3 & 0 & 0.033 & 0.179 & 0.405 \\
\hline KLHDC4 & 54758 & $8.66 \mathrm{E}+06$ & 18571 & 26 & 2 & 0 & 0.033 & 0.082 & 0.201 \\
\hline ZAN & 7455 & $8.45 \mathrm{E}+06$ & 19030 & 25 & 2 & 0 & 0.176 & 0.482 & 0.984 \\
\hline DKFZP586P0123 & 26005 & $7.38 \mathrm{E}+06$ & 20579 & 18 & 2 & 0 & 0.165 & 0.477 & 0.853 \\
\hline UNC13C & 440279 & $7.38 \mathrm{E}+06$ & 20835 & 17 & 2 & 0 & 0.115 & 0.372 & 0.694 \\
\hline FLJ39155 & 133584 & $7.38 \mathrm{E}+06$ & 21333 & 15 & 2 & 0 & 0.176 & 0.482 & 0.942 \\
\hline RASSF6 & 166824 & $7.38 \mathrm{E}+06$ & 21543 & 15 & 2 & 0 & 0.062 & 0.183 & 0.405 \\
\hline $\mathrm{OVCH} 1$ & 341350 & $5.79 \mathrm{E}+06$ & 24923 & 1 & 2 & 0 & 0.165 & 0.477 & 0.853 \\
\hline Q9H5FO_HUMAN & & NA & NA & NA & 3 & 0 & $<0.001$ & 0.004 & 0.009 \\
\hline Q9H8A7_HUMAN & & NA & NA & NA & 2 & 0 & 0.165 & 0.477 & 0.853 \\
\hline$F L 46481$ & 389197 & NA & NA & NA & 2 & 0 & 0.062 & 0.183 & 0.405 \\
\hline XR_017918.1 & & NA & NA & NA & 2 & 0 & 0.062 & 0.183 & 0.405 \\
\hline LOC441136 & 441136 & NA & NA & NA & 2 & 0 & 0.009 & 0.079 & 0.201 \\
\hline
\end{tabular}

This table shows all genes from Supplementary Table S7 of Jones et al. [43] listed by strength of MeSHOP similarity score (via the $\mathrm{L}_{2}$ of log-p of overlapping terms only metric). NA, no MeSHOP available.

Table 11 MeSHOP similarity analysis of known breast cancer genes with seven or more observed mutations

\begin{tabular}{lcc}
\hline Chromosomal location/gene(s) & Mutations observed & MeSHOP similarity rank \\
\hline TP53 & 38 & 1 \\
PIK3CA & 33 & 55 \\
Chr17:37833600-38018803/ERBB2 & 21 & 2 \\
GATA3 & 15 & 773 \\
chr8:37353781-37489508/FGFR1/ZNF703 & 15 & $191 / 8,493$ \\
chr8:128504497-128948225/MYC & 15 & 19 \\
Chr11:69224506-69556470/CCND1 & 11 & 9 \\
MAP3K1 & 9 & 417 \\
Chr20:52065876-52723895/ZNF217 & 9 & 2,102 \\
PTEN & 7 & 12 \\
NCOR1 & 7 & 360 \\
CDKN2A & 7 & 6 \\
CDH1 & 7 & 11
\end{tabular}

Genes known to be implicated in breast cancer from Supplementary Table 4 of [45] are compared to the MeSHOP similarity ranking of human genes for breast neoplasms. The rows in italics highlight genes with a MeSHOP similarity rank less than 13 . 
Table 12 Highest ranked breast cancer gene candidates with MeSHOP similarity analysis

\begin{tabular}{llcc}
\hline Rank & Gene & $\begin{array}{c}\text { Probability of } \\
\text { oncogenicity }\end{array}$ & $\begin{array}{c}\text { MeSHOP similarity } \\
\text { rank }\end{array}$ \\
\hline $\mathbf{1}$ & MAP3K1 & $\mathbf{1}$ & $\mathbf{4 1 7}$ \\
2 & TBX3 & 0.99996 & 2513 \\
3 & TTN & 0.99952 & 1842 \\
$\mathbf{4}$ & NCOR1 & $\mathbf{0 . 9 9 8 3 5}$ & $\mathbf{3 6 0}$ \\
5 & MTMR4 & 0.98201 & 10529 \\
6 & MAP3K13 & 0.97383 & 9545 \\
$\mathbf{7}$ & CDKN1B & $\mathbf{0 . 9 6 3 7 8}$ & $\mathbf{2 2}$ \\
8 & DIDO1 & 0.90433 & 4931 \\
9 & SMARCD1 & 0.88007 & 3098 \\
$\mathbf{1 0}$ & CASP8 & $\mathbf{0 . 8 6 4 6 2}$ & $\mathbf{1 5 0}$ \\
\hline
\end{tabular}

We list the top ten breast cancer candidate genes from Supplementary Table 5 of [45], ranked by probability of oncogenicity. Genes in bold are in the top 500 by MeSHOP similarity rank.

analysis shows neither genomic length nor transcript length have significant predictive ability in our current validation sets, suggesting these previous biases are no longer foretelling of future gene-disease association. Advances in methodology such as high-resolution microarrays and sequencing may have removed the influence of the bias, suggesting that literature bias favoring well-studied genes may correct itself as more genes become better characterized.

The $\mathrm{L}_{2}$ of log-p of overlapping terms similarity metric outperformed all other methods, but many methods performed nearly as well. The highest-performing metrics all focus on the terms shared by the profiles and emphasize terms unlikely to be associated by chance. The $\mathrm{L}_{2}$ metric is conceptually straightforward and supported by all statistical and mathematical analysis packages. The fact that multiple metrics perform well suggests that the performance may be constrained by the data properties. The quality of $\mathrm{MeSH}$ annotations appears high, as $\mathrm{MeSH}$ annotations are assigned by domain experts at the NLM. However, the limited time that can be devoted to any single article necessarily means that the assigned terms are limited to the main topics of the articles. MeSHOPs and comparison methods may benefit from more comprehensive annotation assignments based on automated full-text analysis.

\section{Comparison to other MeSH-related methods}

A related but different method of CoPub Discovery [55] seeks to identify hidden links between genes and diseases through shared keywords in MEDLINE ${ }^{\circledR}$ abstracts. They assess predictions using historical entries from before 2000, identifying genes and keywords from entries using text mining. As a comparison scores, they employ a straightforward linear summation of the minimum score of the shared MeSH terms. In contrast, our predictions use the larger corpus of MEDLINE ${ }^{\circledR}$ up to 2007, and our MeSHOPs-based method builds on curated $\mathrm{MeSH}$ terms and Entrez Gene article links, enabling a broad range of applications. We also evaluate measures of $\mathrm{MeSH}$ term association strength to generate $\mathrm{MeSHOPs}$ and many different comparison scores for comparing gene and disease MeSHOPs.

The text mining method reported by Srinivasan [56] extracts $\mathrm{MeSH}$ terms of importance to summarize a set of articles related to an entity. This considers common $\mathrm{MeSH}$ terms between profiles as potential paths to connect two entities. MeSHOPs use a statistical scoring method to compute $P$-values for the profiles, and further evaluates a large number of different methods for generating and comparing the MeSHOPs, analyzing all terms between profiles computationally.

Sarkar et al. [14] use weighted profiles of MeSH terms and visualize the terms as a MeSH cloud to summarize a collection of documents retrieved from MEDLINE ${ }^{\circledR}$ and to facilitate further investigation of related articles in MEDLINE ${ }^{\circledR}$.

MeSHOPs share conceptual similarities with the method of CAESAR [22]. CAESAR scores the occurrences of extracted keyword terms in an authoritative text that summarizes the topic of interest. MeSHOPs use all relevant articles, each with individual associated $\mathrm{MeSH}$ biomedical terms, reflecting both the main directions of research and associated topics.

\section{Future directions}

The use of MeSHOPs to infer term attachment and predict novel associations need not necessarily be limited to the attachment of disease terms to genes and vice versa. This methodology could be expanded to the attachment of any subset of MeSH terms to biomedical topics of interest.

MeSHOPs could be explored for gene-disease associations in other species than human - preliminary analysis predicting mouse genes associated with $\mathrm{MeSH}$ disease terms have achieved similar performance results. Human disease gene prioritization has been shown to be improved through incorporation of mouse phenotype data [25], suggesting incorporation of orthology data could be used to improve predictions. New candidates for complex diseases could also be evaluated through their similarity to known genes related to the disease of interest, as seen in an analysis by Taniya et al. [57] for rheumatoid arthritis and prostate cancer using several other sources of gene annotation.

\section{Conclusions}

MeSHOPs quantitatively represent the MeSH biomedical terms associated with any defined entity with an identified set of MEDLINE ${ }^{\circledR}$-indexed papers. Results demonstrate MeSHOP similarity can infer functional 
annotation of genes and diseases. Specifically, the similarity between gene MeSHOPs and disease MeSHOPs is highly predictive of future gene-disease ties. Although bibliometric characteristics, such as the number of terms in the disease MeSHOP, are predictive of genedisease association, our best predictions, using $\mathrm{L}_{2}$ of $\log$ p of overlapping terms, achieve a mean AUC of 0.94, an improvement of 0.08 over the mean AUC for the number of disease terms baseline, and an improvement of 0.13 over the mean AUC for the number of gene terms baseline. The consistency of the results over five validation sets duplicated over two sources of gene article links demonstrates that the predictive performance of our method is stable and replicable. Beyond the prediction of annotation, MeSHOP comparison predicts genes with functional roles in disease process, validated using curated gene-disease relationships in CTD and in case studies.

\section{Materials and methods \\ MeSHOP generation for genes and diseases}

We describe here the construction of MeSHOPs - a detailed introduction and establishment of this method is presented elsewhere [31]. A MeSHOP is a quantitative representation of the $\mathrm{MeSH}$ annotations associated with a set of articles where the set is composed of articles that address a specific entity (such as a gene or disease). The computation of a MeSHOP initiates from a set of articles that address a specific entity. Each article has a curator-assigned set of $\mathrm{MeSH}$ terms available in MEDLINE $^{\circledR}$. Comparing the observed frequency of each $\mathrm{MeSH}$ term annotated to a set of articles relative to the background rate for each term returns a measure of over-representation. A MeSHOP is a vector of tuples < $\left(t_{1}, m_{1}\right),\left(t_{2}, m_{2}\right), \ldots\left(t_{w}, m_{n}\right)>$. For each tuple $\left(t_{i}, m_{i}\right)$ in a MeSHOP, $t_{i}$ is a distinct MeSH term in the MeSH vocabulary and $m_{i}$ is the numeric measure of the strength of association of the MeSH term $t_{i}$ to the set of articles (for example, the over-representation measures). To account for the tree structure of $\mathrm{MeSH}$, for each $\mathrm{MeSH}$ term associated with an article, the article is considered associated to all of the parent terms of that MeSH term.

Several scoring metrics have been implemented to report the strength of association between an entity and a MeSH term in a quantitative fashion. A basic measure is the raw count of articles annotated with each term. Such counts can be normalized by dividing the raw count by the total number term annotations for the particular gene or disease to address the degree of annotation. However, counting methods fail to account for statistical significance; the frequency in which term appears in MEDLINE ${ }^{\circledR}$ should be accounted for. To address this deficiency, $P$-values can be computed based on a hypergeometric distribution via Fisher's exact test.
MeSHOPs are generated for each member of a class by assessing the set of all linked MEDLINE ${ }^{\mathbb{R}}$ records for each member. We use Fisher's exact test to determine $P$-values, computed from a $2 \times 2$ contingency table composed of: 1) the frequency of occurrence of the term $t_{i}$ in the set of articles addressing the entity of interest; 2) all articles addressing the entity of interest without the term $t_{i}$; 3) the frequency of the term $t_{i}$ in the background set not addressing the entity of interest; and 4) the remaining number of articles in the background set that do not refer to the term $t_{i}$ and do not address the entity of interest. A universal background of $\mathrm{MeSH}$ term frequency is applied in this case derived from a set of 17 million MEDLINE ${ }^{\circledR}$ articles assigned $\mathrm{MeSH}$ terms. For every MeSH term that occurs in the articles associated with a gene, we compute the statistical significance of the association. Entity class-specific $\mathrm{MeSH}$ frequency backgrounds can be applied for improved visualization when comparisons are not sought as described in [31]; in this paper, however, we use the universal background described here that is common to both genes and diseases.

\section{Inferring novel gene-disease association}

To infer entity-MeSH annotation relationships, we hypothesize that a previously unassociated MeSH term $t$ is likely to be associated with an entity $e$ if the MeSHOP $P_{t}$ for the MeSH term $t$ is highly similar to the entity's MeSHOP $P_{e}$. The scoring of similarity was performed with a panel of formulae presented in Table 3. Once the profiles for each human gene and each disease term in $\mathrm{MeSH}$ were computed, we measured the similarity of each human gene profile against each disease profile.

\section{Quantitative validation of gene-disease similarity measures}

ROC curves were computed for each of the similarity scores evaluated. AUC was measured to assess the accuracy of the scoring metrics. In the case where there are no ties, the ROC curve is composed of horizontal and vertical sections; in the case of ties, diagonal sections also occur. AUC values can be converted to mean rankings by noting that the AUC reports the mean probability that, for a random disease, given a random positive gene and a random negative gene, the positive gene is scored higher than the negative gene. The ranking of the positive is the result of $n-1$ Bernoulli trials, where the positive is compared to each of the negatives. Each 'failure' in this case causes the rank to drop by 1 . The average rank is given by $1+(1-\operatorname{AUC})(n-1)$.

\section{Data sources}

The annual MEDLINE ${ }^{\circledR}$ Baseline releases 2007, 2009 and 2010 were used as the source of $\mathrm{MeSH}$ annotations for articles. All gene-disease co-occurrences (that is, the 
gene and the disease directly linked to the same article) were extracted for each release. Similarly, we manually downloaded snapshots of Entrez Gene, including the links from genes to MEDLINE ${ }^{\mathbb{R}} /$ PubMed $^{\mathbb{R}}$ articles from GeneRIF and gene2pubmed, approximately matched to the date of the MEDLINE ${ }^{\circledR}$ releases. For each MEDLINE $^{\circledR}$ Baseline release matched with Entrez Gene downloaded snapshot, we generated the MeSHOP for each disease in $\mathrm{MeSH}$, the MeSHOP for each human gene using the associated GeneRIF annotation, and the MeSHOP for each human gene using the associated gene2pubmed annotation. We compared each gene MeSHOP with GeneRIF annotation against each disease using the similarity scores. Each gene MeSHOP with gene2pubmed annotation was also compared against each disease using the similarity scores. See Table 13 for details of the size and contents of these datasets. We use the references from the 2007 Entrez Gene snapshot and the 2007 MEDLINE $^{\circledR}$ Baseline to generate MeSHOP similarity scores for all human genes with GeneRIF annotations. The MeSHOP similarity scores for all human genes with gene2pubmed annotations were also generated. These two sets of gene-disease MeSHOP similarity scores were validated for the ability to predict novel co-occurrences of genes and diseases in MEDLINE $^{\circledR}$, as well as the ability to predict new curated gene-disease relationships.

\section{Gene-disease novel co-occurrence validation sets}

To validate the effectiveness of predicting using MeSHOP similarity, we generated predictions using archived versions of all the datasets (MEDLINE ${ }^{\circledR}$ and Entrez Gene), involving data up to 2007. Using more recent versions of MEDLINE ${ }^{\circledR}$ and Entrez Gene, we identify new gene-disease relationships that appeared after 2007. These novel relationships are considered the true positives for validation. We then evaluated the accuracy of the MeSHOP similarity comparison of the
2007 data at predicting novel gene-disease relationships appearing after 2007, quantitatively evaluated using ROC AUC. We also measured the accuracy of the similarity measures at predicting the existing gene-disease relationships up to 2007.

Gene characteristics were extracted from EnsEMBL 53 (April 2009) and these characteristics were mapped to the human genes in Entrez Gene. The genes with mapped gene characteristics were then evaluated for the ability to predict novel gene-disease predictions, providing a baseline to contrast the performance of the MeSHOP similarity predictions.

\section{Novel curated gene-disease relationship validation sets}

Two sets of curated gene-disease relationships were extracted from the CTD. These gene-disease relationships are identified from OMIM and published MEDLINE $^{\circledR}$ literature by CTD curators. The first set was all gene-disease tuples involving $\mathrm{MeSH}$ disease terms downloaded November 2008 (3,630 tuples covering 828 diseases and 2,092 genes for the genes with gene2pubmed-based MeSHOPs, and 3,178 tuples covering 780 diseases and 1,714 genes for the genes with GeneRIFbased MeSHOPs). We compared these relationships with the relationships present in the version of CTD downloaded April 2010, and created a validation set where the 'true positives' composed of all the new tuples present in the April 2010 dataset that were not present in the November 2008 dataset (1,760 new tuples covering 426 diseases and 1,068 genes for the genes with gene2pubmed-based MeSHOPs, and 1,602 new tuples covering 409 diseases and 942 genes for the genes with GeneRIF-based MeSHOPs). This validation set was used to evaluate the performance of the MeSHOP similarity scores generated using MEDLINE ${ }^{\circledR}$ and Entrez Gene data up to 2007. Gene characteristic baselines were also evaluated to contrast the performance of the MeSHOP similarity scores.

Table 13 Datasets used in the analysis with details on size and relevant contents

\begin{tabular}{|c|c|c|c|}
\hline Dataset & February 2007 & January 2009 & April 2010 \\
\hline \multicolumn{4}{|c|}{ Entrez Gene (including gene2pubmed and GeneRIF) } \\
\hline Total genes & $2,460,748$ & $4,710,910$ & $5,999,558$ \\
\hline \multirow[t]{2}{*}{ Human genes } & 38,604 & 40,183 & 45,423 \\
\hline & Baseline 2007 (Nov 2006) & Baseline 2009 (Nov 2008) & Baseline 2010 (Nov 2009) \\
\hline \multicolumn{4}{|l|}{ MEDLINE ${ }^{\circledR}$} \\
\hline Total articles & $16,120,073$ & $17,764,232$ & $18,502,915$ \\
\hline \multicolumn{4}{|c|}{ gene2pubmed (Linking Entrez Gene and MEDLINE ${ }^{\circledR}$} \\
\hline Total links & $3,081,413$ & $12,960,489$ & $5,979,167$ \\
\hline Total human gene links & 272,123 & 445,650 & 527,821 \\
\hline
\end{tabular}

Although the number of human genes has not increased much over the years, the number of non-human links has increased substantially since 2007 , while the human gene links have increased at a more moderate rate. Previously, MEDLINE ${ }^{\circledR} /$ PubMed ${ }^{\circledR}$ links from genomic sequence were propagated to all related genes. This practice was discontinued in March 2009, resulting (at the time) in a $60 \%$ decrease in links and the disparity in the number of overall links from 2009 to 2010. 
Predictive performance for pre-existing relationships

To confirm the expected capacity for MeSHOP comparisons to detect established gene-disease relationships, we evaluated the performance of similarity measures at ranking pre-existing gene-disease relationships (relationships reported in the literature before 2008). This assessment was performed for gene-disease co-occurrences obtained from Entrez Gene and MEDLINE ${ }^{\circledR}$ as well as from the November 2008 relationships curated from CTD.

\section{Examining overlapping terms}

While MeSHOP similarity scores provide a quantitative assessment of the similarity of a gene MeSHOP and a disease MeSHOP, examining the overlapping terms between the profiles and the associated $P$-values could also provide insight into the medical topic areas that are shared by the MeSHOPs and provide clues into how the concepts can be related. We provide a link when browsing the MeSHOP similarity scores online to the list of overlapping $\mathrm{MeSH}$ terms between the two profiles, ordered by the similarity of the $P$-values for the shared terms. An example showing the top 100 shared terms between PAX6 and anirida is provided in Table 14, showing both general terms relating to genetics and heritable diseases such as 'mutation, missense' and 'exons', as well as terms specifically linking the gene to disease such as 'chromosomes, human, pair 11' and 'cataract'.

\section{Implementation}

The analysis was performed using Python 2.5.2 [58], XSLT [59], and the MySQL database system 5.0.51a [60]. Fisher's exact test $P$-values were computed using the $R$ statistics package [61]. Results were generated using 50 CPUs of a compute cluster running under Grid Engine 6.2 [62]. A typical cluster machine is a 64-bit dual processor $3 \mathrm{GHz}$ Intel Xeon with $16 \mathrm{~GB}$ of RAM.

Datasets were downloaded from Entrez Gene [63] including the gene2pubmed and GeneRIF links - and

Table 14 Top 100 terms shared by the MeSHOPs of PAX6 and aniridia

\begin{tabular}{|c|c|c|c|}
\hline Common MeSH term & Gene MeSHOP $P$-value & Disease MeSHOP $P$-value & Score \\
\hline DNA mutational analysis & $0.00 E+00$ & $0.00 \mathrm{E}+00$ & $0.00 \mathrm{e}+0$ \\
\hline Pedigree & $0.00 \mathrm{E}+00$ & $0.00 \mathrm{E}+00$ & $0.00 e+0$ \\
\hline Polymorphism, single-stranded conformational & $1.40 \mathrm{E}-44$ & $1.67 \mathrm{E}-42$ & $1.66 \mathrm{e}-42$ \\
\hline Humans & $6.82 \mathrm{E}-24$ & $0.00 \mathrm{E}+00$ & $6.82 e-24$ \\
\hline Exons & 8.53E-24 & $2.98 \mathrm{E}-23$ & $2.13 e-23$ \\
\hline Mutation, missense & $1.45 \mathrm{E}-23$ & $9.72 \mathrm{E}-21$ & $9.70 e-21$ \\
\hline Chromosomes, human, pair 11 & 2.73E-20 & $0.00 \mathrm{E}+00$ & $2.73 e-20$ \\
\hline Codon, nonsense & 1.15E-18 & $1.96 \mathrm{E}-21$ & $1.15 e-18$ \\
\hline Cataract & $2.37 \mathrm{E}-17$ & $0.00 \mathrm{E}+00$ & $2.37 e-17$ \\
\hline Point mutation & $6.94 \mathrm{E}-17$ & 7.02E-18 & $6.24 \mathrm{e}-17$ \\
\hline Frameshift mutation & $9.77 \mathrm{E}-15$ & $2.11 \mathrm{E}-21$ & $9.77 e-15$ \\
\hline DNA primers & $5.27 \mathrm{E}-12$ & 2.69E-15 & $5.27 e-12$ \\
\hline Fovea centralis & $2.41 E-16$ & $6.03 \mathrm{E}-11$ & $6.03 e-11$ \\
\hline Introns & $5.01 \mathrm{E}-10$ & $2.15 \mathrm{E}-13$ & $5.01 e-10$ \\
\hline Nystagmus, congenital & 9.55E-10 & $3.29 \mathrm{E}-11$ & $9.22 \mathrm{e}-10$ \\
\hline Genes, dominant & 7.39E-09 & $2.45 \mathrm{E}-14$ & $7.39 e-9$ \\
\hline Asian continental ancestry group & $2.23 \mathrm{E}-16$ & 1.07E-08 & $1.07 e-8$ \\
\hline Lens, crystalline & $2.40 \mathrm{E}-08$ & $5.62 \mathrm{E}-24$ & $2.40 \mathrm{e}-8$ \\
\hline Alternative splicing & $6.14 \mathrm{E}-13$ & 7.97E-08 & 7.97e-8 \\
\hline Corneal opacity & 2.45E-06 & $1.47 \mathrm{E}-16$ & $2.45 e-6$ \\
\hline Child, preschool & 3.63E-06 & $3.08 \mathrm{E}-44$ & $3.63 e-6$ \\
\hline Family health & $1.03 \mathrm{E}-05$ & 1.69E-07 & $1.01 e-5$ \\
\hline Gene expression regulation, developmental & $2.46 \mathrm{E}-15$ & $1.04 \mathrm{E}-05$ & $1.04 e-5$ \\
\hline Genes, homeobox & 1.40E-05 & $6.32 \mathrm{E}-09$ & $1.40 \mathrm{e}-5$ \\
\hline Adolescent & $1.92 \mathrm{E}-05$ & $1.71 \mathrm{E}-18$ & $1.92 e-5$ \\
\hline Conserved sequence & $6.20 \mathrm{E}-06$ & $1.18 \mathrm{E}-04$ & $1.12 \mathrm{e}-4$ \\
\hline Heterozygote & 1.15E-04 & $6.94 \mathrm{E}-08$ & $1.15 e-4$ \\
\hline Radiation hybrid mapping & $1.72 \mathrm{E}-05$ & 1.50E-04 & $1.33 e-4$ \\
\hline Alleles & 2.29E-04 & 4.17E-05 & $1.87 \mathrm{e}-4$ \\
\hline
\end{tabular}


Table 14 Top 100 terms shared by the MeSHOPs of PAX6 and aniridia (Continued)

\begin{tabular}{|c|c|c|c|}
\hline Abnormalities, multiple & $2.91 \mathrm{E}-04$ & $0.00 \mathrm{E}+00$ & $2.91 e-4$ \\
\hline Iris & $3.45 \mathrm{E}-04$ & $0.00 \mathrm{E}+00$ & $3.45 e-4$ \\
\hline Blepharoptosis & $4.54 \mathrm{E}-04$ & 4.55E-08 & $4.53 e-4$ \\
\hline WAGR syndrome & $5.13 \mathrm{E}-04$ & $0.00 \mathrm{E}+00$ & $5.13 e-4$ \\
\hline Tomography, optical coherence & $1.14 \mathrm{E}-03$ & 4.47E-04 & $6.97 e-4$ \\
\hline Corpus callosum & $6.03 \mathrm{E}-07$ & $9.38 \mathrm{E}-04$ & $9.38 \mathrm{e}-4$ \\
\hline Pregnancy & $9.62 \mathrm{E}-01$ & $9.60 \mathrm{E}-01$ & $1.09 \mathrm{e}-3$ \\
\hline Open reading frames & $2.56 \mathrm{E}-10$ & $1.12 \mathrm{E}-03$ & $1.12 \mathrm{e}-3$ \\
\hline Forkhead transcription factors & $1.27 \mathrm{E}-03$ & $1.95 \mathrm{E}-05$ & $1.25 e-3$ \\
\hline Face & $1.42 \mathrm{E}-03$ & $3.94 \mathrm{E}-05$ & $1.38 \mathrm{e}-3$ \\
\hline Nucleic acid heteroduplexes & $2.02 \mathrm{E}-04$ & $1.73 \mathrm{E}-03$ & $1.53 e-3$ \\
\hline In situ hybridization, fluorescence & $1.61 \mathrm{E}-03$ & $3.22 \mathrm{E}-29$ & $1.61 e-3$ \\
\hline Gene deletion & $1.65 \mathrm{E}-03$ & 1.77E-21 & $1.65 e-3$ \\
\hline PAX9 transcription factor & $8.46 \mathrm{E}-04$ & $2.50 \mathrm{E}-03$ & $1.66 \mathrm{e}-3$ \\
\hline Proprotein convertase 1 & $1.71 \mathrm{E}-03$ & $1.27 \mathrm{E}-05$ & $1.69 e-3$ \\
\hline Ectopia lentis & $1.81 \mathrm{E}-03$ & $1.42 \mathrm{E}-05$ & $1.79 e-3$ \\
\hline Albinism, ocular & $1.86 \mathrm{E}-03$ & $3.98 \mathrm{E}-14$ & $1.86 e-3$ \\
\hline Databases, nucleic acid & 3.09E-04 & $2.63 \mathrm{E}-03$ & $2.32 \mathrm{e}-3$ \\
\hline India & $1.13 \mathrm{E}-04$ & $2.79 \mathrm{E}-03$ & $2.68 \mathrm{e}-3$ \\
\hline Amino acid substitution & $2.03 \mathrm{E}-06$ & 3.07E-03 & $3.06 \mathrm{e}-3$ \\
\hline Transcriptional activation & $1.10 \mathrm{E}-23$ & $3.22 \mathrm{E}-03$ & $3.22 \mathrm{e}-3$ \\
\hline Genetic markers & $3.43 \mathrm{E}-03$ & $1.71 \mathrm{E}-10$ & $3.43 e-3$ \\
\hline Anophthalmos & 5.77E-03 & $1.45 \mathrm{E}-04$ & $5.63 e-3$ \\
\hline 3' Untranslated regions & $8.26 \mathrm{E}-06$ & $5.66 \mathrm{E}-03$ & $5.65 e-3$ \\
\hline Young adult & $1.18 \mathrm{E}-02$ & 4.91E-03 & $6.84 \mathrm{e}-3$ \\
\hline Limbus corneae & $7.58 \mathrm{E}-03$ & $1.48 \mathrm{E}-18$ & $7.58 \mathrm{e}-3$ \\
\hline RNA, transfer, Lys & 4.19E-03 & $1.23 \mathrm{E}-02$ & $8.16 e-3$ \\
\hline Dna transposable elements & $9.49 \mathrm{E}-03$ & $9.94 \mathrm{E}-04$ & $8.50 \mathrm{e}-3$ \\
\hline Heteroduplex analysis & 4.54E-03 & $1.34 \mathrm{E}-02$ & $8.84 \mathrm{e}-3$ \\
\hline Chromosome deletion & $9.12 \mathrm{E}-03$ & $0.00 \mathrm{E}+00$ & $9.12 e-3$ \\
\hline Homozygote & 1.09E-02 & $1.29 \mathrm{E}-03$ & $9.57 e-3$ \\
\hline Otx transcription factors & $5.70 \mathrm{E}-06$ & $1.00 \mathrm{E}-02$ & $9.99 e-3$ \\
\hline Genetic predisposition to disease & $1.16 \mathrm{E}-02$ & $8.84 \mathrm{E}-05$ & $1.15 e-2$ \\
\hline Microphthalmos & 1.17E-02 & $2.34 \mathrm{E}-12$ & $1.17 e-2$ \\
\hline Vision, low & $1.24 \mathrm{E}-02$ & $6.65 \mathrm{E}-04$ & $1.17 e-2$ \\
\hline Optic nerve & $1.26 \mathrm{E}-02$ & $5.64 \mathrm{E}-08$ & $1.26 \mathrm{e}-2$ \\
\hline Exotropia & $7.21 \mathrm{E}-03$ & $2.12 \mathrm{E}-02$ & $1.40 \mathrm{e}-2$ \\
\hline Cytosine & $2.70 \mathrm{E}-03$ & $2.15 \mathrm{E}-02$ & $1.88 \mathrm{e}-2$ \\
\hline Magnetic resonance imaging & 4.92E-04 & $1.96 \mathrm{E}-02$ & $1.92 \mathrm{e}-2$ \\
\hline United States & $9.81 \mathrm{E}-01$ & $1.00 \mathrm{E}+00$ & $1.93 e-2$ \\
\hline Trabecular meshwork & $2.22 \mathrm{E}-02$ & $2.11 \mathrm{E}-03$ & $2.01 e-2$ \\
\hline Polymorphism, restriction fragment length & $2.30 \mathrm{E}-02$ & 7.12E-04 & $2.23 e-2$ \\
\hline Body patterning & $3.32 \mathrm{E}-03$ & $2.62 \mathrm{E}-02$ & $2.29 \mathrm{e}-2$ \\
\hline Dichotic listening tests & $1.21 \mathrm{E}-02$ & $3.55 \mathrm{E}-02$ & $2.34 \mathrm{e}-2$ \\
\hline Multigene family & $2.46 \mathrm{E}-02$ & 8.37E-04 & $2.38 \mathrm{e}-2$ \\
\hline 3T3 Cells & $3.00 \mathrm{E}-06$ & 2.67E-02 & $2.67 e-2$ \\
\hline Cognition disorders & 4.77E-02 & 2.05E-02 & $2.72 \mathrm{e}-2$ \\
\hline Esotropia & $1.42 \mathrm{E}-02$ & 4.14E-02 & $2.72 \mathrm{e}-2$ \\
\hline Mutagenesis, insertional & $4.08 \mathrm{E}-03$ & $3.18 \mathrm{E}-02$ & $2.77 e-2$ \\
\hline Endothelium, corneal & 2.94E-02 & $1.06 \mathrm{E}-04$ & $2.93 e-2$ \\
\hline Restriction mapping & $3.25 \mathrm{E}-02$ & $2.53 \mathrm{E}-06$ & $3.25 e-2$ \\
\hline Thymine & 4.15E-02 & 7.24E-03 & $3.43 e-2$ \\
\hline
\end{tabular}


Table 14 Top 100 terms shared by the MeSHOPs of PAX6 and aniridia (Continued)

\begin{tabular}{|c|c|c|c|}
\hline Sequence homology, amino acid & $3.52 \mathrm{E}-02$ & $3.31 \mathrm{E}-04$ & $3.49 e-2$ \\
\hline Glutamine & $5.38 \mathrm{E}-03$ & 4.13E-02 & $3.59 \mathrm{e}-2$ \\
\hline Chromosomes, human, pair 10 & $1.97 \mathrm{E}-02$ & $5.72 \mathrm{E}-02$ & $3.75 e-2$ \\
\hline Nervous system malformations & $5.11 \mathrm{E}-02$ & $9.30 \mathrm{E}-02$ & $4.18 \mathrm{e}-2$ \\
\hline Organ specificity & $2.36 \mathrm{E}-01$ & $1.90 \mathrm{E}-01$ & $4.62 e-2$ \\
\hline Catenins & $6.22 \mathrm{E}-02$ & $1.59 \mathrm{E}-02$ & $4.63 e-2$ \\
\hline Genetic heterogeneity & $2.45 \mathrm{E}-02$ & 7.09E-02 & $4.64 \mathrm{e}-2$ \\
\hline Brain-derived neurotrophic factor & 5.07E-02 & $6.24 \mathrm{E}-07$ & $5.07 e-2$ \\
\hline Chromosomes, human, pair 12 & $2.70 \mathrm{E}-02$ & 7.77E-02 & $5.08 \mathrm{e}-2$ \\
\hline Leucine zippers & $1.64 \mathrm{E}-04$ & $5.28 \mathrm{E}-02$ & $5.26 \mathrm{e}-2$ \\
\hline Verbal behavior & 2.09E-01 & $1.53 \mathrm{E}-01$ & $5.57 e-2$ \\
\hline Mice, transgenic & $6.20 \mathrm{E}-02$ & $5.89 \mathrm{E}-03$ & $5.61 e-2$ \\
\hline DNA fingerprinting & $9.30 \mathrm{E}-02$ & $3.44 \mathrm{E}-02$ & $5.85 e-2$ \\
\hline Sequence alignment & $1.69 \mathrm{E}-02$ & $7.59 \mathrm{E}-02$ & $5.90 \mathrm{e}-2$ \\
\hline Autistic disorder & $9.48 \mathrm{E}-02$ & $3.57 \mathrm{E}-02$ & $5.91 \mathrm{e}-2$ \\
\hline Fluorescent antibody technique, indirect & $9.84 \mathrm{E}-02$ & $3.83 \mathrm{E}-02$ & $6.00 \mathrm{e}-2$ \\
\hline Age factors & 9.37E-01 & 9.97E-01 & $6.03 e-2$ \\
\hline
\end{tabular}

The top 50 most similar MeSH terms of the $235 \mathrm{MeSH}$ terms shared by both the MeSHOP for aniridia and the MeSHOP for PAX6 are presented here. The $P$-value of the term in the gene MeSHOP and the disease MeSHOP are presented, and ordered by the difference in the two $P$-values.

MEDLINE ${ }^{\circledR}$ via a lease from the NLM [64]. The CTD validation set was taken from the gene-disease relationships dataset [65].

\section{Availability of source code}

Source code is available for the gene and disease profile analysis [66], and for the evaluation and validation of results [67].

\section{Abbreviations}

AD: Alzheimer disease; AUC: area under the ROC curve; CTD: Comparative Toxicogenomics Database; GeneRIF: Gene Reference Into Function; GWAS: genome-wide association study; ID: identifier; MAP: mean average precision MeSH: Medical Subject Heading; MeSHOP: Medical Subject Heading Overrepresentation Profile; NCBI: National Center for Biotechnology Information; NLM: US National Library of Medicine; OMIM: Online Mendelian Inheritance in Man; PCR: polymerase chain reaction; ROC: receiver operating characteristic.

\section{Acknowledgements}

This work was supported by the Canadian Institutes for Health Research (to WWW); the Ontario Institute for Cancer Research through funding by the government of Ontario (to BFFO); the National Sciences and Engineering Research Council of Canada (to WWW and WAC); the Michael Smith Foundation for Health Research (MSFHR; to WWW and WAC); the National Institute of General Medical Sciences (R01GM084875 to WWW); and the Canadian Institutes of Health Research/MSFHR Strategic Training Program in Bioinformatics (to WAC). The authors are grateful to Leon French, Paul Pavlidis, Lars Arvestad and Raf Podowski for comments and discussion on the research and Joseph Yamada for help with the website.

\section{Author details}

${ }^{1}$ Bioinformatics Graduate Program, Centre for Molecular Medicine and Therapeutics at the Child and Family Research Institute, University of British Columbia, 980 W. 28th Ave, Vancouver, V5Z 4H4, Canada. ${ }^{2}$ Department of Cells and Systems Biology, Ontario Institute for Cancer Research, University of Toronto, 101 College Street, Toronto, M5G 0A3, Canada. ${ }^{3}$ Department of
Medical Genetics, Centre for Molecular Medicine and Therapeutics at the Child and Family Research Institute, University of British Columbia, $980 \mathrm{~W}$. 28th Ave, Vancouver, V5Z 4H4, Canada.

\section{Authors' contributions}

All authors contributed to the design of the method and the analysis and interpretation of the data. WAC implemented and carried out the study. All authors read and approved the final manuscript.

\section{Competing interests}

The authors declare that they have no competing interests.

Received: 28 April 2012 Revised: 11 September 2012

Accepted: 28 September 2012 Published: 28 September 2012

\section{References}

1. Makrythanasis $P$, Antonarakis SE: From sequence to functional understanding: the difficult road ahead. Genome Med 2011, 3:21.

2. Tiffin N, Andrade-Navarro M, Perez-Iratxeta C: Linking genes to diseases: it's all in the data. Genome Med 2009, 1:77.

3. Sayers E, Barrett T, Benson D, Bryant S, Canese K, Chetvernin V, Church D, Dicuccio M, Edgar R, Federhen S, Feolo M, Geer L, Helmberg W, Kapustin Y, Landsman D, Lipman D, Madden T, Maglott D, Miller V, Mizrachi I, Ostell J, Pruitt K, Schuler G, Sequeira E, Sherry S, Shumway M, Sirotkin K, Souvorov A, Starchenko G, Tatusova T, et al: Database resources of the National Center for Biotechnology Information. Nucleic Acids Res 2009, 37: D5-D15.

4. Hirschman L, Hayes WS, Valencia A: Knowledge acquisition from the biomedical literature. In Semantic Web. Edited by: Mayer B. New York, NY: Humana Press; 2007:53-81.

5. Jensen LJ, Saric J, Bork P: Literature mining for the biologist: from information retrieval to biological discovery. Nat Rev Genet 2006, 7:119-129.

6. Medical Subject Headings: Chapter 11 - Relationships in Medical Subject Headings. [http://www.nlm.nih.gov/mesh/meshrels.html]

7. Grossmann S, Bauer S, Robinson PN, Vingron M: Improved detection of overrepresentation of Gene-Ontology annotations with parent child analysis. Bioinformatics 2007, 23:3024-3031.

8. Prüfer K, Muetzel B, Do H-H, Weiss $G$, Khaitovich P, Rahm E, Pääbo S, Lachmann M, Enard W: FUNC: a package for detecting significant 
associations between gene sets and ontological annotations. $B M C$ Bioinformatics 2007, 8:41.

9. Nakazato T, Bono H, Matsuda H, Takagi T: Gendoo: Functional profiling of gene and disease features using MeSH vocabulary. Nucleic Acids Res 2009, 37:W166-W169.

10. Bundschus M, Dejori M, Stetter M, Tresp V, Kriegel H-P: Extraction of semantic biomedical relations from text using conditional random fields. BMC Bioinformatics 2008, 9:207.

11. Nakazato T, Takinaka T, Mizuguchi $\mathrm{H}$, Matsuda $\mathrm{H}$, Bono H, Asogawa M: BioCompass: A novel functional inference tool that utilizes MeSH hierarchy to analyze groups of genes. Silico Biol 2007, 8:53-61.

12. Kumar V: Omics and literature mining. In Bioinformatics for Omics Data: Methods and Protocols. Edited by: Mayer B. Totowa, NJ: Humana Press; 2011:457-477.

13. Good BM, Kawas E, Kuo BY-L, Wilkinson MD: iHOPerator: user-scripting a personalized bioinformatics Web, starting with the iHOP website. BMC Bioinformatics 2006, 7:534.

14. Sarkar IN, Schenk R, Miller H, Norton CN: LigerCat: using 'MeSH Clouds from journal, article, or gene citations to facilitate the identification of relevant biomedical literature center for clinical and translational science, University of Vermont, Burlington, VT MBLWHOI Library, Marine. Information Retrieval 2009, 1:563-567.

15. Li S, Wu L, Zhang Z: Constructing biological networks through combined literature mining and microarray analysis: a LMMA approach. Bioinformatics 2006, 22:2143-2150.

16. Rodríguez-Penagos C, Salgado H, Martínez-Flores I, Collado-Vides J: Automatic reconstruction of a bacterial regulatory network using Natural Language Processing. BMC Bioinformatics 2007, 8:293.

17. Kim H, Park H, Drake BL: Extracting unrecognized gene relationships from the biomedical literature via matrix factorizations. BMC Bioinformatics 2007, 8(Suppl 9):S6.

18. Perez-Iratxeta C, Bork P, Andrade-Navarro MA: Update of the G2D tool for prioritization of gene candidates to inherited diseases. Nucleic Acids Res 2007, 35:W212-216.

19. Loscalzo J, Kohane I, Barabasi A-L: Human disease classification in the postgenomic era: a complex systems approach to human pathobiology. Mol Systems Biol 2007, 3:124.

20. Lage K, Karlberg EO, Størling ZM, Ólason PÍ, Pedersen AG, Rigina O, Hinsby AM, Tümer Z, Pociot F, Tommerup N, Moreau Y, Brunak S: A human phenome-interactome network of protein complexes implicated in genetic disorders. Nat Biotechnol 2007, 25:309-316.

21. Hristovski D, Peterlin B, Mitchell J, Humphrey SM: Using literature-based discovery to identify disease candidate genes. Int I Med Informatics 2005, 74:289-298.

22. Gaulton KJ, Mohlke KL, Vision TJ: A computational system to select candidate genes for complex human traits. Bioinformatics 2007, 23:1132-1140.

23. Yu S, Van Vooren S, Tranchevent L-C, De Moor B, Moreau Y: Comparison of vocabularies, representations and ranking algorithms for gene prioritization by text mining. Bioinformatics 2008, 24:1119-25.

24. Aerts $S$, Lambrechts D, Maity S, Van Loo P, Coessens B, De Smet F, Tranchevent L-C, De Moor B, Marynen P, Hassan B, Carmeliet P, Moreau Y: Gene prioritization through genomic data fusion. Nat Biotechnol 2006, 24:537-544.

25. Chen J, Xu H, Aronow BJ, Jegga AG: Improved human disease candidate gene prioritization using mouse phenotype. BMC Bioinformatics 2007, 8:392

26. Cornet $\mathrm{R}$, de Keizer N: Forty years of SNOMED: a literature review. BMC Med Inform Decis Mak 2008, 8(Suppl 1):S2.

27. Bodenreider O: The Unified Medical Language System (UMLS): integrating biomedical terminology. Nucleic Acids Res 2004, 32:D267-270.

28. Osborne JD, Flatow J, Holko M, Lin SM, Kibbe W, Zhu LJ, Danila MI, Feng G, Chisholm RL: Annotating the human genome with Disease Ontology. BMC Genomics 2009, 10(Suppl 1):S6.

29. Hamosh A, Scott AF, Amberger JS, Bocchini C, McKusick V: Online Mendelian Inheritance in Man (OMIM), a knowledgebase of human genes and genetic disorders. Nucleic Acids Res 2005, 33:D514-517.

30. Bauer-Mehren A, Bundschus M, Rautschka M, Mayer M, Sanz F, Furlong LI: Gene-disease network analysis reveals functional modules in mendelian, complex and environmental diseases. PloS One 2011, 6:e20284.
31. Cheung WA, Wasserman WW: Quantitative biomedical annotation using medical subject heading over-representation profiles (MeSHOPs). BMC bioinformatics 2012, 13(1):249, doi:10.1186/1471-2105-13-249.

32. Mitchell JA, Aronson AR, Mork JG, Folk LC, Humphrey SM, Ward JM: Gene indexing: characterization and analysis of NLM's GeneRIFs. AMIA Annu Symp Proc 2003, 460-464.

33. Indexing Principles for Category C. [http://www.nlm.nih.gov/mesh/ indman/chapter_23.html].

34. Yetisgen-Yildiz M, Pratt W: A new evaluation methodology for literaturebased discovery systems. J Biomed Informat 2009, 42:633-643.

35. Leong HS, Kipling D: Text-based over-representation analysis of microarray gene lists with annotation bias. Nucleic Acids Res 2009, 37:e79.

36. Davis AP, King BL, Mockus S, Murphy CG, Saraceni-Richards C, Rosenstein M, Wiegers T, Mattingly CJ: The Comparative Toxicogenomics Database: update 2011. Nucleic Acids Res 2011, 39:D1067-172.

37. Wiegers TC, Davis AP, Cohen KB, Hirschman L, Mattingly CJ: Text mining and manual curation of chemical-gene-disease networks for the comparative toxicogenomics database (CTD). BMC Bioinformatics 2009, 10:326.

38. Davis AP, Wiegers TC, Rosenstein MC, Mattingly CJ: MEDIC: a practical disease vocabulary used at the Comparative Toxicogenomics Database. Database 2012, 2012:bar065.

39. Fontaine J-F, Priller F, Barbosa-Silva A, Andrade-Navarro M: Génie: literaturebased gene prioritization at multi genomic scale. Nucleic Acids Res 2011, 39:W455-461.

40. Cortes-Canteli M, Paul J, Norris EH, Bronstein R, Ahn HJ, Zamolodchikov D, Bhuvanendran S, Fenz KM, Strickland S: Fibrinogen and beta-amyloid association alters thrombosis and fibrinolysis: a possible contributing factor to Alzheimer's disease. Neuron 2010, 66:695-709.

41. Ahn HJ, Zamolodchikov D, Cortes-Canteli M, Norris EH, Glickman JF, Strickland S: Alzheimer's disease peptide beta-amyloid interacts with fibrinogen and induces its oligomerization. Proc Natl Acad Sci USA 2010, 107:21812-21817.

42. Sladek R, Rocheleau G, Rung J, Dina C, Shen L, Serre D, Boutin P, Vincent D, Belisle A, Hadjadj S, Balkau B, Heude B, Charpentier G, Hudson TJ, Montpetit A, Pshezhetsky AV, Prentki M, Posner Bl, Balding DJ, Meyre D, Polychronakos C, Froguel P: A genome-wide association study identifies novel risk loci for type 2 diabetes. Nature 2007, 445:881-885.

43. Jones $S$, Zhang $X$, Parsons DW, Lin JC-H, Leary RJ, Angenendt P, Mankoo P, Carter H, Kamiyama H, Jimeno A, Hong S-M, Fu B, Lin M-T, Calhoun ES, Kamiyama M, Walter K, Nikolskaya T, Nikolsky Y, Hartigan J, Smith DR, Hidalgo M, Leach SD, Klein AP, Jaffee EM, Goggins M, Maitra A, lacobuzioDonahue C, Eshleman JR, Kern SE, Hruban RH, et al: Core signaling pathways in human pancreatic cancers revealed by global genomic analyses. Science 2008, 321:1801-1806.

44. Mees ST, Mardin WA, Wendel C, Baeumer N, Willscher E, Senninger N, Schleicher C, Colombo-Benkmann M, Haier J: EP300 - a miRNA-regulated metastasis suppressor gene in ductal adenocarcinomas of the pancreas. Int J Cancer 2009, 126:114-124.

45. Stephens PJ, Tarpey PS, Davies H, Van Loo P, Greenman C, Wedge DC, NikZainal S, Martin S, Varela I, Bignell GR, Yates LR, Papaemmanuil E, Beare D, Butler A, Cheverton A, Gamble J, Hinton J, Jia M, Jayakumar A, Jones D, Latimer C, Lau KW, McLaren S, McBride DJ, Menzies A, Mudie L, Raine K, Rad R, Chapman MS, Teague J, et al: The landscape of cancer genes and mutational processes in breast cancer. Nature 2012, 486:400-404.

46. Medical Subject Over-representation Profiles.. [http://meshop.oicr.on.ca/ meshop/].

47. Browse Gene MeSHOP Literature Results. [http://meshop.oicr.on.ca/ meshop/gene_browse.html].

48. Browse Disease MeSHOP Literature Results. [http://meshop.oicr.on.ca/ meshop/disease_browse.html].

49. Browse Gene-Disease Predictions/Validation. [http://meshop.oicr.on.ca/ meshop/browse_results.html].

50. Inferring Novel Gene-Disease Associations Using Medical Subject Heading Over-representation Profiles Supplementary Material for Genome Medicine. [http://meshop.oicr.on.ca/meshop/gmed2012.html].

51. Agarwal $P$, Searls DB: Can literature analysis identify innovation drivers in drug discovery?. Nat Rev Drug Discov 2009, 8:865-878.

52. Gillis J, Pavlidis P: The impact of multifunctional genes on 'guilt by association' analysis. PLOS ONE 2011, 6:e17258. 
53. López-Bigas N, Ouzounis C: Genome-wide identification of genes likely to be involved in human genetic disease. Nucleic Acids Res 2004, 32:3108-3114.

54. Adie EA, Adams RR, Evans KL, Porteous DJ, Pickard BS: Speeding disease gene discovery by sequence based candidate prioritization. $B M C$ Bioinformatics 2005, 6:55.

55. Frijters R, van Vugt M, Smeets R, van Schaik R, de Vlieg J, Alkema W: Literature mining for the discovery of hidden connections between drugs, genes and diseases. PLoS Comput Biol 2010, 6:e1000943.

56. Srinivasan P: Text mining: Generating hypotheses from MEDLINE. J Am Soc Information Sci Technol 2004, 55:396-413.

57. Taniya T, Tanaka S, Yamaguchi-Kabata Y, Hanaoka H, Yamasaki C, Maekawa H, Barrero Ra, Lenhard B, Datta MW, Shimoyama M, Bumgarner R, Chakraborty R, Hopkinson I, Jia L, Hide W, Auffray C, Minoshima S, Imanishi T, Gojobori T: A prioritization analysis of disease association by data-mining of functional annotation of human genes. Genomics 2011, 99:1-9.

58. Python Programming Language - Official Website.. [http://python.org/].

59. The XSLT C library for GNOME libxslt. [http://xmlsoft.org/XSLT/].

60. MySQL. [http://dev.mysql.com].

61. R Core Team: R: A Language and Environment for Statistical Computing Vienna, Austria: R Foundation for Statistical Computing; 2012.

62. Oracle Grid Engine. [http://www.oracle.com/us/products/tools/oracle-gridengine-075549.html].

63. Entrez Gene FTP. [ftp://ftp.ncbi.nlm.nih.gov/gene/]

64. Leasing Data from the National Library of Medicine ${ }^{\circledR}$. [http://www.nlm. nih.gov/databases/leased.html].

65. CTD Data Downloads: Gene-disease associations. [http://ctdbase.org/ downloads/\#gd].

66. Source code for Generating Medical Subject Heading OverRepresentation Profiles. [https://github.com/wac/meshop/].

67. Source Code to compare and compute performance results from two MeSHOP gene disease prediction results. [https://github.com/wac/cmpmeshop/].

doi:10.1186/gm376

Cite this article as: Cheung et al:: Inferring novel gene-disease associations using Medical Subject Heading Over-representation Profiles. Genome Medicine 2012 4:75.

\section{Submit your next manuscript to BioMed Central and take full advantage of:}

- Convenient online submission

- Thorough peer review

- No space constraints or color figure charges

- Immediate publication on acceptance

- Inclusion in PubMed, CAS, Scopus and Google Scholar

- Research which is freely available for redistribution

Submit your manuscript at www.biomedcentral.com/submit 